\title{
Observing Scattering Mechanisms of Bubbled Freshwater Lake Ice Using Polarimetric RADARSAT-2 (C-Band) and UW-Scat (X- and Ku-Bands)
}

\author{
Grant E. Gunn ${ }^{\circledR}$, Member, IEEE, Claude R. Duguay, Donald K. Atwood, Member, IEEE, \\ Joshua King, and Peter Toose
}

\begin{abstract}
A winter time series of ground-based (X- and Ku-bands) scatterometer and spaceborne synthetic aperture radar (SAR) (C-band) fully polarimetric observations coincident with in situ snow and ice measurements are used to identify the dominant scattering mechanism in bubbled freshwater lake ice in the Hudson Bay Lowlands near Churchill, Manitoba. Scatterometer observations identify two physical sources of backscatter from the ice cover: the snow-ice and ice-water interfaces. Backscatter time series at all frequencies show increases from the ice-water interface prior to the inclusion of tubular bubbles in the ice column based on in situ observations, indicating scattering mechanisms independent of double-bounce scatter. The co-polarized phase difference of interactions at the ice-water interface from both scatterometer and SAR observations is centered at $0^{\circ}$ during the time series, also indicating a scattering regime other than double bounce. A Yamaguchi three-component decomposition of the RADARSAT-2 C-band time series is presented, which suggests the dominant scattering mechanism to be single-bounce off the ice-water interface with appreciable surface roughness or preferentially oriented facets, regardless of the presence, absence, or density of tubular bubble inclusions. This paper builds on newly established evidence of single-bounce scattering mechanism for freshwater lake ice and is the first to present a winter time series of ground-based and spaceborne fully polarimetric active microwave observations with polarimetric decompositions for bubbled freshwater lake ice.
\end{abstract}

Index Terms-Frequency-modulated continuous wave (FMCW), lake ice, polarimetry, synthetic aperture radar (SAR).

Manuscript received August 25, 2017; revised November 1, 2017; accepted December 19, 2017. Date of publication January 30, 2018; date of current version April 20, 2018. This work was supported by the European Space Agency (ESTEC) under Contract 4000103590/11/NL/FF/fk and Contract 4000106960/12/NL/BJ/lf. The work of G. E. Gunn and C. R. Duguay was supported by the Natural Sciences and Engineering Research Council of Canada. (Corresponding author: Grant E. Gunn.)

G. E. Gunn is with the Department of Geography, Environment, and Spatial Sciences, Michigan State University, East Lansing, MI 48824 USA (e-mail: gunng@msu.edu).

C. R. Duguay is with the Department of Geography and Environmental Management, University of Waterloo, Waterloo, ON N2L 3G1, Canada (e-mail: crduguay@uwaterloo.ca).

D. K. Atwood was with the Michigan Tech Research Institute, Ann Arbor, MI 48105 USA (e-mail: dkatwood@mtu.edu).

J. King and P. Toose are with the Climate Research Division, Environment and Climate Change Canada, Toronto, ON M3H 5T4, Canada (e-mail: Joshua.king@canada.ca; Peter.Toose@canada.ca).

Color versions of one or more of the figures in this paper are available online at http://ieeexplore.iee.org.

Digital Object Identifier 10.1109/TGRS.2017.2786158

\section{INTRODUCTION}

T AKES comprise $2 \%$ of globally available freshwater and play a significant role in the biological, chemical, and physical processes in the cold-region water cycle [1]. The majority of lakes are located in the Northern Hemisphere and can occupy up to $40 \%$ of the local landscape in many regions [2]. The presence of lakes influences surface-atmosphere energy exchanges which modifies the surface radiative properties, affecting local and regional climate through thermal moderation [2]. Knowledge of the surface and thermal state of lakes is useful in numerical weather prediction or regional climate models for regions where lakes comprise a large portion of the landscape [3]. In addition, Arctic and sub-Arctic freshwater lake ice can be used as an indicator for change in climate, as Arctic regions have exhibited amplified warming compared to lower latitudes [4].

The number of manual lake ice monitoring stations within the Canadian Ice Database has dropped significantly since the late 1990s [5]. Existing stations are restricted to populated regions and accessible coastal areas, missing remote areas of the Arctic. Recent studies have indicated that the use of satellite microwave remote sensing can provide lake ice parameter observation including lake ice phenology [6], ice thickness [7]-[10], and areas that are frozen to bed [11]-[15]. The use of active microwave has been identified as most suitable for the observation of lake ice in the Arctic as a result of its high spatial resolution compared to that of passive microwave sensors on the order of meters versus kilometers. Furthermore, microwave wavelengths are capable of penetrating through clouds and are independent of incoming solar radiation. Backscatter models for lake ice at common synthetic aperture radar (SAR) frequencies have been developed using C-band acquisitions as training or validation data [16]-[18]. Bubbles within ice have typically been modeled as spherical utilizing a distribution function of bubble density [17], or as a combination of spherical and cylindrical bubbles [16], [18] utilizing radiative transfer theory to simulate backscatter. Roughness characteristics at the air, snow, and ice interfaces are typically hypothesized or fit through the use of SAR observations as training data. 
Recent developments in active microwave SAR technology with systems like RADARSAT-2 or PALSAR-2 permit the use of quad-polarized acquisitions (VV, $\mathrm{HH}, \mathrm{HV}$, and $\mathrm{VH}$ ), phase information, and the observation of the target scattering matrix that allows for the extraction of the contribution of scattering components within each ground pixel [19]. Earlier studies [12], [20], [21] have attributed backscatter observed at the sensor from lake ice to be the result of double bounce caused by tubular bubbles within the ice volume and off the ice-water interface. Single-acquisition L-band polarimetric decomposition results from [22] present polarimetric decomposition of the scattering matrix from large-scale oblate methane ebullition bubbles, reporting that surface bounce at the ice-water interface is the dominant scattering mechanism in several lakes on the Alaskan Coastal Plain (ACP) and Northern Seward Peninsula. In addition, recent studies have introduced the case for single bounce from the ice-water interface as the dominant scattering mechanism in freshwater lake ice containing tubular bubbles using polarimetric SAR acquisitions at L- and C-bands [23], [24] and a full-wave simulation model [25].

This paper presents a time series of in situ groundbased $\mathrm{X}^{-}$and Ku-band observations collected during the 2009-2010 winter using the University of Waterloo sledborne scatterometer (UW-Scat) temporally coincident with spaceborne C-band RADARSAT-2 quad-polarized acquisitions to assess the scattering mechanism in tubular bubbled freshwater ice on Malcolm Ramsay Lake (near Churchill, MB, Canada). Section II provides background information and equations necessary for the analysis presented in this paper, and the study site is presented in Section III. Section IV presents phase and backscatter observations for interaction near the snow-ice and ice-water interfaces observed using UW-Scat at four static sites with in situ snow and ice observations conducted adjacent to the scatterometer footprint. UW-Scat observations are supplemented by co-polarized phase difference observations using RADARSAT-2. In addition, a time series of the Yamaguchi three-component polarimetric decomposition is presented that details the proportion of dominant scattering mechanisms [26]. Section VII provides a discussion of the presented findings. This paper presents the first time-series analysis of polarimetric decompositions of freshwater lake ice using RADARSAT-2 for the purpose of examining the classic double-bounce scatter hypothesis in bubbled freshwater lake ice.

\section{BACKGROUND}

Backscatter from lakes is dependent on: 1) the difference in permittivity properties of the media in the sensor field of view and 2) microwave interaction with scattering centers at media interfaces or within the snow or ice volume. In the case of lake ice, the sensor field of view observes a combination of water, freshwater ice, and snow $\left(\mathrm{H}_{2} \mathrm{O}\right.$ in liquid and solid states), and the interfaces between them. The complex relative permittivity of a medium $\left(\varepsilon^{*}\right)$ is given by

$$
\varepsilon^{*}=\varepsilon^{\prime}+j \varepsilon^{\prime \prime}
$$

where $\varepsilon^{\prime}$ is the real component and represents the relative dielectric constant and $\varepsilon^{\prime \prime}$ is the relative dielectric loss, with $j$ denoting that $\varepsilon^{\prime \prime}$ is the imaginary component (equal to $\sqrt{-1}$ ) [27]. For the remainder of this paper, the cumbersome "relative" term will be omitted when referring to permittivity or dielectric constant, but refer to the electrical properties relative to a vacuum. The permittivity of pure liquid water varies across the microwave region of the electromagnetic spectrum due to dependencies on temperature and frequency, associated with Debye style dispersion [27]. Therefore, the dielectric constant $\left(\varepsilon^{\prime}\right)$ of pure liquid water at $0{ }^{\circ} \mathrm{C}$ is $\sim 90, \sim 40$, and $\sim 20$ for $\mathrm{C}-, \mathrm{X}_{-}$, and Ku-bands, respectively, with a high loss factor of approximately $\varepsilon^{\prime \prime}=36$ across the C- to Ku-band range [28]. Conversely, the highly bonded molecular structure of solid-state $\mathrm{H}_{2} \mathrm{O}$ results in a lowloss medium, where $\varepsilon^{\prime}$ has experimentally measured values of $\varepsilon^{\prime}=3.17$ with negligible $\varepsilon^{\prime \prime}$ of 0.00065 , and a slight temperature dependence below $0{ }^{\circ} \mathrm{C}\left(\varepsilon^{\prime}=3.163-3.189\right.$ at $-28^{\circ} \mathrm{C}$ to $0{ }^{\circ} \mathrm{C}$, respectively) across the microwave range [29]. The permittivity of ice is also affected by the presence of impurities including bubble inclusions. The effective bubbledice permittivity $\varepsilon_{\text {bubble }}^{\prime}$ can be computed using empirical mixing formulas utilized in [16], including the fraction of air inclusions $(p)$ in the following equation:

$$
\varepsilon_{\text {bubble }}^{\prime}=\varepsilon_{\text {ice }}^{\prime}\left(\frac{1+2 p y}{1-p y}\right)
$$

where

$$
y=\left(\frac{1-\varepsilon_{\text {ice }}^{\prime}}{1+2\left(\varepsilon_{\text {ice }}^{\prime}\right)}\right) .
$$

The contrast in permittivity between water and ice influences, the amount of radiation reflected $(R)$ or transmitted $(\Gamma)$ across the boundary layer, governed by the Fresnel equations in (4)-(6), assuming the interface is smooth with respect to the incident wavelength. Transmission across the air-snow and snow-ice interfaces is quite high in both parallel and perpendicular polarizations, with dry snow and ice being lowloss mediums. At the ice-water interface, the mismatch in dielectrics results in near-specular reflection, the proportion which can be computed from

$$
\begin{aligned}
R_{\perp} & =\frac{\varepsilon_{\text {ice }}^{*} \cos \theta_{1}-\varepsilon_{\text {air }}^{*} \cos \theta_{2}}{\varepsilon_{\text {ice }}^{*} \cos \theta_{1}+\varepsilon_{\text {air }}^{*} \cos \theta_{2}} \\
R_{\|} & =\frac{\varepsilon_{\text {air }}^{*} \cos \theta_{1}-\varepsilon_{\text {ice }}^{*} \cos \theta_{2}}{\varepsilon_{\text {air }}^{*} \cos \theta_{1}+\varepsilon_{\text {ice }}^{*} \cos \theta_{2}} \\
\Gamma & =1-R
\end{aligned}
$$

where $R_{\perp}$ and $R_{\|}$are the Fresnel reflection coefficients for horizontally and vertically polarized waves, respectively [27].

\section{A. Scattering Sources From Snow-Covered Lake Ice}

1) Interface Surfaces: The magnitude of the signal scattered back to the sensor from a surface is proportional to the surface roughness, which is quantified by the correlation length (measures the statistical similarities of the height of multiple points on a surface), and the root mean square (RMS) of height deviations from the surface mean [22]. As height deviations 
TABLE I

(a) RECOMMENDED SPACING OF OBSERVATIONS TO COMPUTE RMS Surface Roughness in Medium of Differential PermitTivity FOR SNOW AND ICE. (b) RMS SURFACE ROUGHNESS THRESHOLD VALUES FOR THE FRAUNHOFFER SMOOTH SURFACE CRITERION

(a)

\begin{tabular}{|c|c|c|c|c|}
\hline & $\begin{array}{c}\begin{array}{c}\text { Frequency } \\
(\mathrm{GHz})\end{array} \\
\end{array}$ & $\begin{array}{c}\text { Air } \\
\left(\varepsilon^{\prime}=1\right)\end{array}$ & $\begin{array}{c}\text { Snow }\left(\varepsilon^{\prime}=\right. \\
1.5)\end{array}$ & $\begin{array}{c}\text { Ice }\left(\varepsilon^{\prime}=\right. \\
3.17) \\
\end{array}$ \\
\hline C-band & 5.405 & 0.56 & 0.37 & 0.31 \\
\hline $\mathrm{X}$-band & 9.6 & 0.31 & 0.21 & 0.18 \\
\hline Ku-band & 17.2 & 0.17 & 0.12 & 0.10 \\
\hline \multicolumn{5}{|c|}{ (b) } \\
\hline & \multicolumn{2}{|c|}{ Snow/Ice Interface } & \multicolumn{2}{|c|}{ Ice/Water Interface } \\
\hline & $18^{\circ}$ & $45^{\circ}$ & $18^{\circ}$ & $45^{\circ}$ \\
\hline C-band & 0.12 & 0.16 & 0.10 & 0.14 \\
\hline $\mathrm{X}$-band & 0.07 & 0.09 & 0.06 & 0.08 \\
\hline $\mathrm{Ku}-\mathrm{band}$ & 0.04 & 0.05 & 0.03 & 0.04 \\
\hline
\end{tabular}

approach the size of the incident wavelength, the surface scatter becomes increasingly diffuse (incoherent), elevating backscatter observed at the sensor if the sensor and receiver are co-located and at a nonzero incidence angle. Backscatter caused by surface roughness becomes pronounced when height deviations at the surface are greater than $\left(\lambda /\left(32 \cos \theta_{i}\right)\right)$, known as the Fraunhoffer criterion, and is dependent on the wavelength $(\lambda)$ utilized. The in situ estimation of RMS surface roughness for microwave studies is difficult, as the spacing of measurements should be $<0.1 \lambda$ [27]. The Fraunhoffer criterion for the range of incidence angles utilized in this paper, and the recommended spacing of in situ observations to quantify RMS roughness at the air-snow, snow-ice, and ice-water interfaces is provided in Table I. Note that the snow-ice and ice-water interface criteria are smaller as the wavelength shortens in media of increased permittivity, given through

$$
\omega / \frac{c}{\sqrt{\varepsilon^{\prime}}}
$$

where $\omega$ is the frequency under observation, $c$ is the speed of light, and $\varepsilon^{\prime}$ is the real component of the relative permittivity [27]. The Fraunhoffer criterion values in Table I utilize $\varepsilon^{\prime}=2.25$ for a bulk snowpack and $\varepsilon^{\prime}=3.17$ for pure freshwater ice. Roughness metrics of the ice-water interface have typically been utilized as a free parameter in backscatter models, and have not been quantified at the scale necessary for SAR studies. Recent observations of a 1-km ice thickness transect over Toolik Lake in Alaska indicated largescale ice-water interface roughness features with a correlation length of approximately $30 \mathrm{~m}$ [30]; however, the supporting measurements of this paper were at a resolution of $1 \mathrm{~m}^{2}$, which is insufficient to observe the small wavelength-scale roughness.

Upon freezing to bed, the contrast in permittivity at the bottom of the ice is reduced as ground medium exhibits much lower relative permittivity of $\varepsilon^{\prime}=\sim 8.3$ [31]. The lower contrast in permittivity allows for reduced reflectivity at this interface and ultimately a drop in backscatter at the sensor [8], [21], [32], [33].

2) Inclusions Within Ice Volume: Gases are expelled into the water column during the ice formation process as ice growth responds to the deficit of heat in the air overlying the lake. If the water column becomes supersaturated with dissolved gases, tubular or teardrop-like bubbles are incorporated into the ice volume parallel to the direction of congelation ice growth. The size and density of bubbles are dependent on gas concentration and ice growth rate [34], [35]. Several studies [12], [13], [15], [16], [18], [21], [36] have identified tubular bubbles as a strong source of increased backscatter over freshwater ice during the observation of single and winter time series of sidelooking aperture radar and SAR observations. Recently, it has been suggested that the diameter and contrast in dielectrics presented by tubular bubbles in the ice volume are insufficient to induce a strong double-bounce mechanism, citing that the layer containing tubular bubbles is an anisotropic homogenous medium with modified permittivity parameters, through the effective medium theory [24], [25], [37]. Instead, it is proposed that backscatter is single bounce from the ice/water interface.

High-density spherical bubbles are occasionally observed in the volume of surface layers; the result of: 1) primary ice development nucleated during a snowfall on calm or turbulent water (i.e., "gray ice") or 2) secondary ice development from previously flooded surface snowpack through cracks in the ice, or from the shoreline when ice is depressed below the hydrostatic water line (i.e., "white ice," or "snow ice") [38]. The resultant ice types with spherical bubble inclusions of $0.5-1 \mathrm{~mm}$ of variable density are identified as a source of depolarizing volume scatter, but the distinction between white and gray ice is not typically made from a radar remote sensing perspective [39], [40].

\section{B. Polarimetric Decomposition}

There are two main categories of polarimetric decomposition algorithms: coherent and incoherent target decompositions. Coherent decompositions express the backscattering matrix [S] as a combination of polarized scattered waves from coherent targets, providing the firstorder estimates of the single-bounce, double-bounce, and volume scatter mechanisms in a pixel [19]. Coherent decompositions are employed to study coherent targets within an observed pixel, with decomposition algorithms contributed by Pauli [41], Krogager [41], Cameron et al. [42], and Touzi and Charbonneau [43]. However, coherent decomposition algorithms ignore the noisy speckle typified by single look complex SAR acquisitions, which can modify and otherwise distort the physical properties of the target. In addition, the use of coherent target decomposition is advantageous for the analysis of pure targets (i.e., man-made objects) of which the scattering response can be completely expressed through the measured scattering matrix $[\mathbf{S}]$. Otherwise, the decomposition analysis of distributed scatterers must be conducted using incoherent decompositions [19].

Incoherent polarimetric decompositions statistically characterize the complex scattering behavior of naturally distributed 
targets through the use of the covariance or coherency matrix. The presence of additive (system) and multiplicative (speckle) noise inherent in SAR acquisitions is reduced by observing second-order polarimetric representations represented by the $3 \times 3$ Hermitian average covariance $\langle[\mathbf{C}]\rangle$ or coherency $\langle[\mathbf{T}]\rangle$ matrices, which represent equivalent polarimetric information [44]

$$
\mathbf{T}=\left[\begin{array}{lll}
T_{11} & T_{12} & T_{13} \\
T_{12}^{*} & T_{22} & T_{23} \\
T_{13}^{*} & T_{23}^{*} & T_{33}
\end{array}\right]
$$

where the superscript $*$ represents the conjugate. The Freeman and Durden decomposition [45] models the $\langle[\mathbf{T}]\rangle$ matrix to be composed of three scattering mechanisms: surface ([ $\left.\left.T_{\text {surface }}\right]\right)$, double bounce $\left[T_{\text {double }}\right]$, and volume scatter ([ $\left.\left.T_{\text {volume }}\right]\right)$

$$
[\mathbf{T}]=P_{s}\left[T_{\text {surface }}\right]+P_{d}\left[T_{\text {double }}\right]+P_{v}\left[T_{\text {volume }}\right]
$$

where $P_{s}, P_{d}$, and $P_{v}$ are the power of each scattering component within the total power returned to the sensor [44]. The surface component ( $\left.T_{\text {surface }}\right)$ is modeled by a first-order Bragg scattering surface with zero depolarization, and in the case of smooth surfaces, negligible cross-polarization [46]. The double-bounce component $\left(T_{\text {double }}\right)$ is modeled as a multiple scattering interaction from a dihedral corner reflector of surfaces with differing permittivity properties, whereby incident radiation undergoes the Fresnel reflection at both horizontal and vertical interfaces. The volume scattering component $\left(T_{\text {volume }}\right)$ is modeled as a cloud of dipole scatterers that utilizes a probability density function that prescribes the dipole orientation. The Freeman and Durden decomposition [45] is extended by Yamaguchi et al. [26] with an additional helix scattering component that identifies complex man-made urban targets (developed by Krogager and Freeman [47]) and further modification of the orientation angle distribution of dipoles within the volume scattering component. In situations where the scene is composed of natural distributed targets, the helix component is negligible, and the Yamaguchi decomposition reverts to three components. The resultant Freeman and Durden and Yamaguchi three-component decompositions yield similar results; therefore, only the results from the Yamaguchi decomposition are presented in the following.

Few studies have conducted polarimetric decomposition for freshwater ice. Using a time series of RADARSAT-2 acquisitions under Pauli decomposition, Van der Sanden and Drouin [48] observed the double-bounce component to produce the highest coefficient of determination $\left(R^{2}\right)$ of many polarimetric parameters with river ice types, but did not report the associated power parameters. Conversely, Engram et al. [22], [23] observed a positive correlation between L-band PALSAR surface-bounce component of the coherency matrix $\left(T_{11}\right)$ and density of large $(0.01-1 \mathrm{~m})$ methane ebullition bubbles for ice-covered lakes in the ACP and the North Seward Peninsula (NSP). Values of the surface roughness component were the highest reported $(-12$ and $-9 \mathrm{~dB})$ compared to double bounce $(-20$ and $-17 \mathrm{~dB})$ and volume scatter $(-24$ and $-21 \mathrm{~dB})$ for the ACP and NSP, respectively [22]. In addition, a drop in the surface-bounce

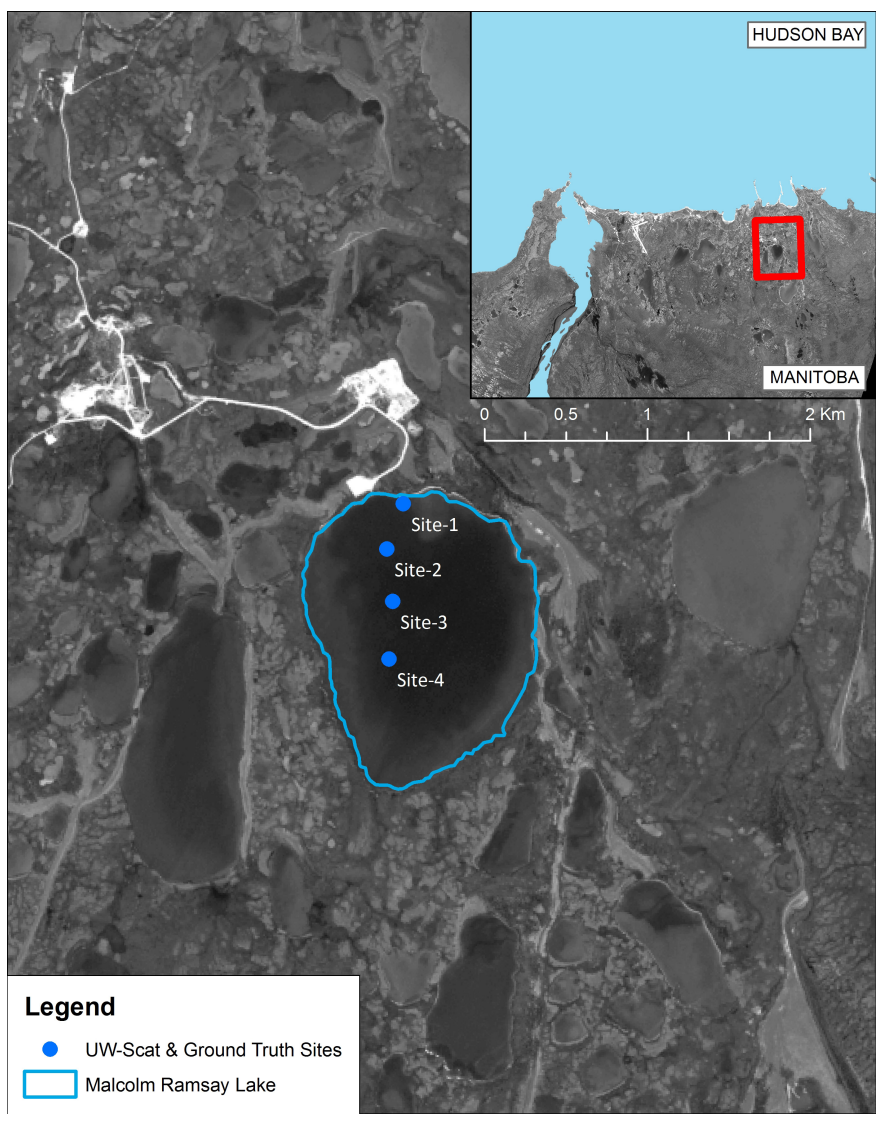

Fig. 1. UW-Scat static observation sites on Malcolm Ramsay Lake, near Churchill, MB, Canada.

component was reported upon the lake freezing to bed (removing the high dielectric-contrast ice-water interface) [23]. The increase in the surface bounce component relative to bubble density was inferred to be related to the modification ice surface roughness with the incorporation of bubbles at the icewater interface.

\section{Study Site and Meteorological Observations}

The experimental site for this study is Malcolm Ramsay Lake (formerly Lake 58), situated approximately $20 \mathrm{~km}$ east of Churchill, MB, Canada, $\left(58.7221^{\circ} \mathrm{N}, 93.7845^{\circ} \mathrm{W}\right)$ in the Hudson Bay Lowlands region (Fig. 1). The lake covers an area of approximately $2 \mathrm{~km}^{2}$, with the lake bed comprising patches of organics, sediment, and rocks, and mean and maximum depths are 2.4 and $3.2 \mathrm{~m}$, respectively [8]. The region surrounding Malcolm Ramsay is located in the juncture of three ecological zones: tundra, tundra-boreal transition, and boreal forest, which run parallel east-west along the coast [49]. The region is relatively flat with a high lake fraction (32\%) and relief features which are the result of glacial deposits [50].

Churchill, MB, Canada, and by extension, Malcolm Ramsay Lake is situated on the south-western shoreline of Hudson Bay, resulting in high sustained average wind speeds $(4.28 \mathrm{~km} / \mathrm{h}$ during the observation period) influencing snowpack and ice development. The annual mean temperature within the 1981-2010 climate average recorded at the Churchill airport 


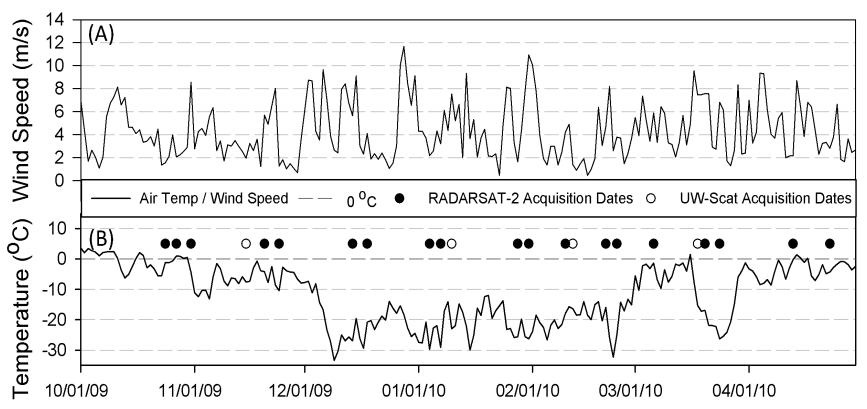

Fig. 2. Average daily meteorological station wind speed and air temperature collected on the north shoreline of Malcolm Ramsay Lake during the UW-Scat and SAR observation periods.

weather station is $-6.9{ }^{\circ} \mathrm{C}$, with below-freezing monthly averages from October to May. The average temperature during the observation period of October 1, 2009 to May 1, 2010 was $-11.7^{\circ} \mathrm{C}$, sufficient to maintain a dry snowpack or ice surface for the duration of radar acquisitions. The monthly average air temperature during the observation period was $4.7^{\circ} \mathrm{C}$ warmer compared to the 1981-2010 climate normal monthly averages.

Meteorological observations were collected by an automated weather station on the north shoreline of Malcolm Ramsay Lake, including air temperature and wind speed/direction (daily averages shown in Fig. 2). The observation period was typified by high-wind events with sustained speeds of up to $8 \mathrm{~m} / \mathrm{s}$, influencing the development of snow distribution and stratigraphy. Scatterometer and SAR acquisitions were collected in subfreezing conditions with the exception of the late winter season (April 23, 2010) when snow melt occurred.

\section{LAKE ICE PROPERTIES AND RADAR OBSERVATIONS}

\section{A. In Situ Snow and Ice Properties}

In situ snow depth, density, and ice thickness observations were conducted along a $100-\mathrm{m}$ transect adjacent to a fixed scatterometer footprint at $0^{\circ}$ azimuth for four sites on Malcolm Ramsay Lake (Fig. 3) regularly starting once the ice was of appreciable depth to support science activity from November 15, 2009 to April 4, 2010. Shoreline observations from an automated camera and a submerged shallow water ice-profiler (SWIP) observe initial ice cover formation on October 14, 2009 [51]. Snow depth was measured every $0.5 \mathrm{~m}$ along the transect using a SnowHydro Magnaprobe [52]. Ice thickness and ice surface types were measured every $25 \mathrm{~m}$ (Fig. 3). Ice cores were extracted from within the scatterometer footprint at the end of the observation period (April 4, 2010) using an auger and ice saw. The depth of the bubbled layer shown in Fig. 3 was recorded from the ice core and inferred for the date of bubble inclusions into the ice for prior measured ice thicknesses.

Traditional snow pits were also conducted adjacent to the scatterometer footprint within a "pit farm," which was located at the start of the 100-m transect outside of the instantaneous field of view, allowing the scatterometer to observe the natural winter evolution of backscatter for snow-covered lake ice. Snow pit measurements were conducted according to [53] and included snow stratigraphy, grain type, grain size, snow density, hardness, and temperature profiles, with measurement parameters summarized in Table II.

Snow and ice properties were observed at static sites in Fig. 3 as part of both intensive observation periods (IOPs), which were temporally coincident with UW-Scat observations, and during extended observation periods (EOPs), where information on snow and ice properties was collected to provide context between IOP observations. In addition, the EOP snow and ice observations were conducted to provide context for RADARSAT-2 overpasses, which were more frequent than UW-Scat observations (Fig. 3).

The snow conditions at sites 1-4 throughout the season were typified by a high-density snow layer comprised rounded grains $\left(\sim 400 \mathrm{~kg} / \mathrm{m}^{3}\right)$ overlying a lower density snow layer comprised columnar grains (depth hoar) $\left(\sim 280 \mathrm{~kg} / \mathrm{m}^{3}\right)$ which still maintained its hardness properties. This pattern was consistent across the lake for snowpacks of depths $(>0.1 \mathrm{~m})$, which was characteristic of slab-to-hoar snow classification found on tundra lakes exposed to sustained wind [54]. The deepest and densest snow was observed throughout the season at site 4, with end-of-season depth and density of $0.18 \mathrm{~m}$ and $389 \mathrm{~kg} / \mathrm{m}^{3}$, respectively.

The long-axis grain size of the depth hoar layers became larger from the beginning to end of the observation period from an average of 1.7 (November 17, 2009) to $4 \mathrm{~mm}$ (March 3, 2010) while the wind slab layer remained relatively consistent, ranging from 1 to $1.5 \mathrm{~mm}$. The increase in longaxis grain size of the depth hoar layer is a result of the high thermal gradient within the snowpack. Average end-ofseason snow depth across the four static observation sites was approximately $0.17 \mathrm{~m}$, with local deviations in snow depth related to redistribution caused by sustained wind from the northwest.

Ice thickness and stratigraphy varied depending on the relative location on Malcolm Ramsay Lake (e.g., proximity to shoreline and bathymetry), with a maximum observed thickness of $1.18 \mathrm{~m}$ at site 3. According to a submersible SWIP at a fixed location close to site 1, freeze-up began on October 15,2009 , measuring sustained ice growth of $0.05 \mathrm{~m}$ in a period of seven days. In situ ice thickness observations indicated that site 1 froze to bed prior to the March 2, 2010 observation when the auger struck the bottom (soft sediment); future observations were abandoned. All sites observed exhibited a marked increase in tubular bubble inclusion near the icewater interface, with an increase in bubble density closer to the ice-water interface dependent on the level of saturation of dissolved gas in the water beneath the ice such that the rate of gas expulsion during ice nucleation is insufficient, incorporating bubbles into the ice volume (Fig. 4). Observed tubular bubble inclusions consistently developed below a layer of completely clear (congelation) ice as inverted elongated teardrops, whereby the bubble origin at the ice-water interface was a semicircle with minimum and maximum diameters of $\sim 1$ and $5 \mathrm{~mm}$, respectively. The semicircle then reduced to a column or "tube" with a diameter of $\sim 0.5 \mathrm{~mm}$ and a total bubble length of 5 to $20 \mathrm{~mm}$.

Tubular bubbles observed in the middle of the ice volume that coincided with high ice growth rates earlier in the season 


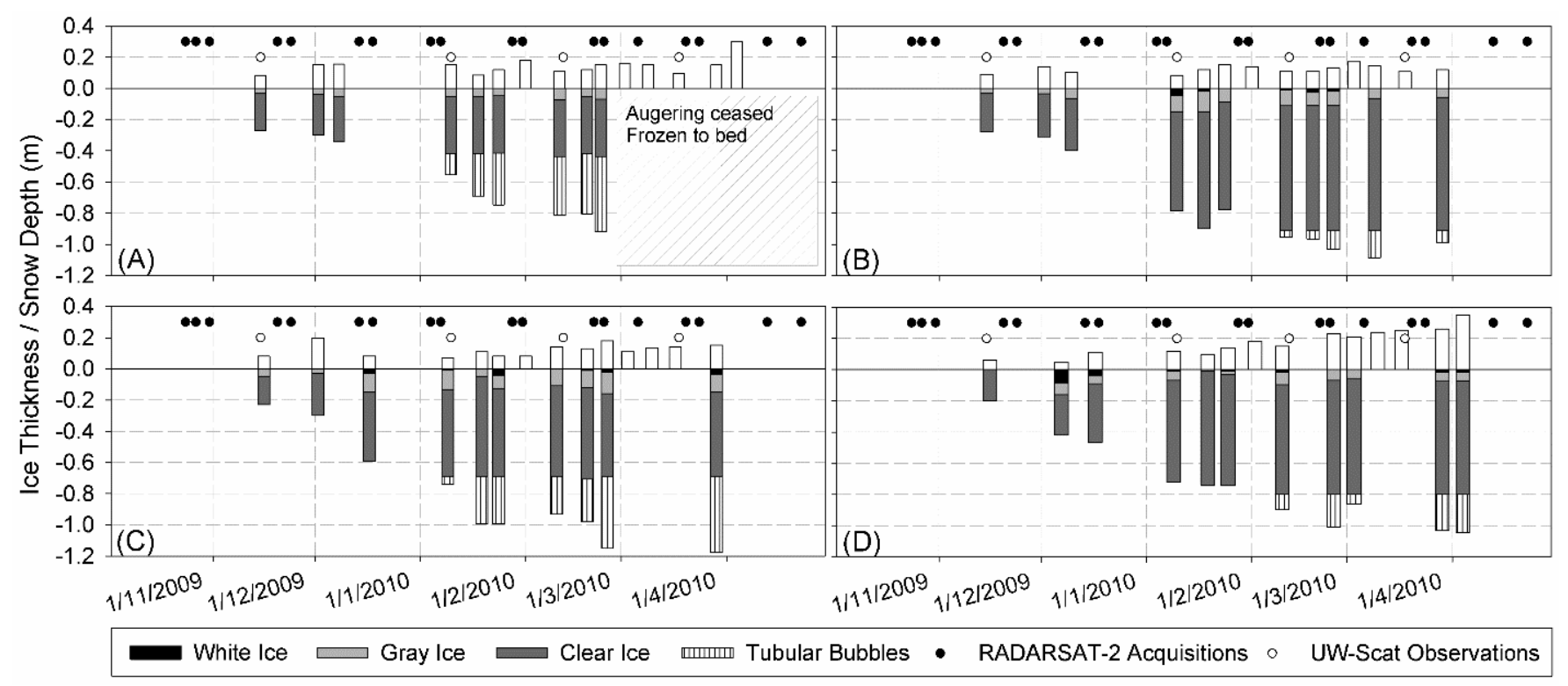

Fig. 3. In situ snow and ice properties for (A)-(D) sites 1-4. Ice stratigraphy is observed from ice cores extracted at the end of the UW-Scat observation period (April 4, 2010) and applied to previous dates to infer the timing of bubbled inclusion. Ice thickness values are averaged from measurements along the $100-\mathrm{m}$ transect.

TABLE II

Summary of Snow And Ice Measurements Collected in SNOW Pit Adjacent to ScATterometer

\begin{tabular}{|c|c|c|c|c|c|}
\hline \multicolumn{3}{|c|}{ Snow } & \multicolumn{3}{|c|}{ Ice } \\
\hline Parameter & Unit & Meas. Device & Parameter & $\begin{array}{c}\text { Un } \\
\text { it }\end{array}$ & Meas. Device \\
\hline Depth & $\mathrm{m}$ & $\begin{array}{c}\text { SnowHydro@ } \\
\text { Magnaprobe } \\
\text { (Sturm and } \\
\text { Holgrem, } \\
1999) \\
\end{array}$ & Thickness & $\mathrm{m}$ & $10 \mathrm{~cm}$ ice auger \\
\hline Density & $\mathrm{kg} / \mathrm{m}^{3}$ & $\begin{array}{c}100 \mathrm{~cm}^{3} \\
\text { density cutter/ } \\
\text { ESC-30 snow } \\
\text { core tube }\end{array}$ & $\begin{array}{l}\text { Surface } \\
\text { Types/ } \\
\text { Thickness }\end{array}$ & $\mathrm{m}$ & $\begin{array}{c}\text { Avalanche Probe in } \\
\text { auger hole }\end{array}$ \\
\hline Grain size & $\mathrm{mm}$ & $\begin{array}{c}\text { Sear grain } \\
\text { size card } \\
\text { (labelled 1-3 } \\
\mathrm{mm}) \\
\end{array}$ & $\begin{array}{l}\text { Layering } \\
\text { (Core) }\end{array}$ & $\mathrm{m}$ & $\begin{array}{c}\text { Kovaks@ Mark II } 9 \\
\mathrm{~cm} \\
\text { Coring system }\end{array}$ \\
\hline Hardness & $\begin{array}{l}\text { Knife/ } \\
\text { Pencil/ } \\
\text { Finger/ } \\
\text { Fist }\end{array}$ & & & & \\
\hline Temp & ${ }^{\circ} \mathrm{C}$ & $\begin{array}{c}\text { Digital } \\
\text { Thermometer }\end{array}$ & & & \\
\hline
\end{tabular}

were approximately $2-3 \mathrm{~mm}$ in diameter (site 1 , at $0.44 \mathrm{~m}$ ) compared to bubbles at the base of the ice cover, which exhibit a diameter of $0.5 \mathrm{~mm}$ (site 2 , ice thickness at $0.91 \mathrm{~m}$ ). Sites 1 and 3 [(A) and (C) in Fig. 3] exhibit the development of tubular bubble inclusions much earlier than sites 2 and 4 [(B) and (D)] and therefore have a thicker bubbled-ice layer, greater bubble density, and larger tubular bubble diameters near the ice-water interface.

Surface ice types composed of high-density spherical microbubbles (snow, gray ice) were observed at all sites, with minimum and maximum layer thicknesses of 0.05 and $0.11 \mathrm{~m}$ at site 4 and sites 2 and 3, respectively.

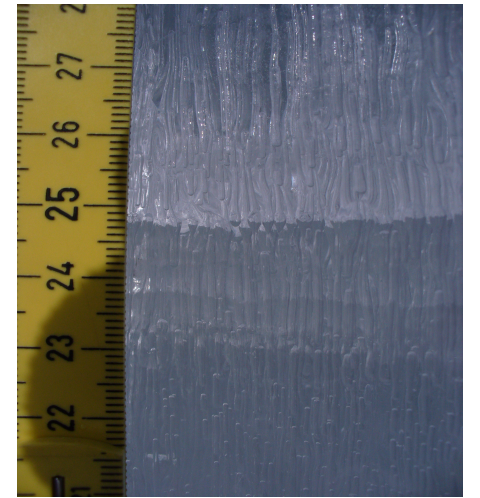

Fig. 4. High-density tubular bubble inclusions between 0.36 and $0.43 \mathrm{~cm}$ from the bottom of ice extracted from site 1 . The bubble length is $>0.1 \mathrm{~m}$, with a diameter of $1.5 \mathrm{~mm}$ at the terminus decreasing to $1 \mathrm{~mm}$ at the "tube."

\section{B. UW-Scat Observations}

Ground-based scatterometer observations were collected using UW-Scat, which is comprised two frequency-modulated continuous wave (FMCW) radars with center frequencies of 9.6 (X-band) and 17.2 GHz (Ku-band) (manufactured by ProSensing Inc.). UW-Scat operates in a switched transmitreceive mode, collecting polarimetric observations (VV, $\mathrm{HH}$, and $\mathrm{VH}$ ) and their relative phase difference. The FMCW radar head is mounted on supports which are maneuvered by a Kipp and Zonen 2ap sun tracker across a $60^{\circ}$ azimuth sweep at $3^{\circ}$ intervals at an incidence angle range of $21^{\circ}-60^{\circ}$. Observations collected at incidence angles larger than $60^{\circ}$ produced a marked drop in signal-tonoise ratio (SNR), precluding their incorporation into the study. Additional UW-Scat sensor information is provided in Table III with an extended sensor description and derivation of the normalized radar cross section (NRCS) provided in [55].

1) UW-Scat Peak Return Isolation: Within the UW-Scat processing procedure, raw data blocks are transformed from 
TABLE III

UW-SCAT SENSOR SPECIFICATIONS

\begin{tabular}{lcc}
\hline Parameter & X-band & Ku-band \\
\hline Output Frequency (GHz) & $9.35-9.85$ & $16.95-17.45$ \\
\hline Transmit Bandwidth (GHz) & 0.5 & 0.5 \\
\hline Transmit Power (dB) & -11.8 & -8.0 \\
\hline Range Resolution (m) & 0.3 & 0.3 \\
\hline Cross-polarization isolation $(\mathrm{dB})$ & $>30$ & $>30$ \\
\hline Sensitivity/Noise Floor $\left(\mathrm{dB} \mathrm{m}^{2} / \mathrm{m}^{2}\right)$ & -50 & -50 \\
\hline Antenna Beam width $\left({ }^{\circ}\right)$ & 4.3 & 5.6 \\
\hline Transmit/Receive polarizations & $\mathrm{VV} / \mathrm{VH} / \mathrm{HH}$ & $\mathrm{VV} / \mathrm{VH} / \mathrm{HH}$ \\
\hline
\end{tabular}

the time to the range domain using a fast Fourier transform. A sky shot is obtained before each scan to estimate the range-dependent transmit leakage, and is coherently subtracted from range bins. Once the leakage removal is completed, the received signal power for all potential range profiles for co- and cross-polarized returns is averaged across the $60^{\circ}$ azimuth sweep at incidence angles determined by the initial scan. The procedure allows for manual selection of the peak signal return within range of the scatterometer, which varies according to the complexity of the target's geometry and permittivity properties. UW-Scat range resolution is influenced by the refractive index of the target $\left(n_{\text {ice }}=\sqrt{\varepsilon_{\text {ice }}^{\prime}}\right)$, and the bandwidth of the sensor (BW) in hertz [56]

$$
r_{\min }=\frac{c}{\left(2 n_{\text {ice }}\right)(\mathrm{BW})}
$$

where $c$ is the speed of light $\left(2.998 \times 10^{8} \mathrm{~m} / \mathrm{s}\right)$. UW-Scat utilizes a BW of $500 \mathrm{MHz}$, resulting in minimum range resolution $\left(r_{\min }\right)$ of $0.17 \mathrm{~m}$ in an ice medium, and $0.3 \mathrm{~m}$ in air [57]. The nominal range resolution implies that scattering interfaces in "thick ice will exhibit a discernable peak in range graphs, providing distance measurements to the snow-ice and ice-water interfaces. Theoretically "thick ice" refers to ice cover thicker than $2 r_{\min }=0.34$, but in the field has been observed to be $>0.4 \mathrm{~m} \mathrm{[58]}$. The range profiles for an early (November 15, 2009) and late (March 29, 2010) winter season UW-Scat observations of site 3 are shown in Fig. 5.

Snow and freshwater lake ice are relatively transmissive mediums due to the low contrast in permittivity at the airsnow and snow-ice interfaces $\left(\varepsilon_{\text {snow }}^{\prime}=1.5\right.$ and $\varepsilon_{\text {ice }}^{\prime}=3.17$ for X- and Ku-bands) [59]. Microwave radiation is, therefore, largely transmitted across the interface and through snow and ice mediums to the ice-water interface, where a high contrast in permittivity is observed ( $\varepsilon_{\text {water }}^{\prime} \sim 40$ and $\sim 20$ for X- and Ku-bands, respectively). The contrast in permittivity results in high reflection of incident microwave radiation at the icewater interface, according to the Fresnel equations (assuming a flat surface) [27]. The reflection of the signal at the ice-water interface was typically the dominant return in the scatterometer field of view, but there were instances where returns from the

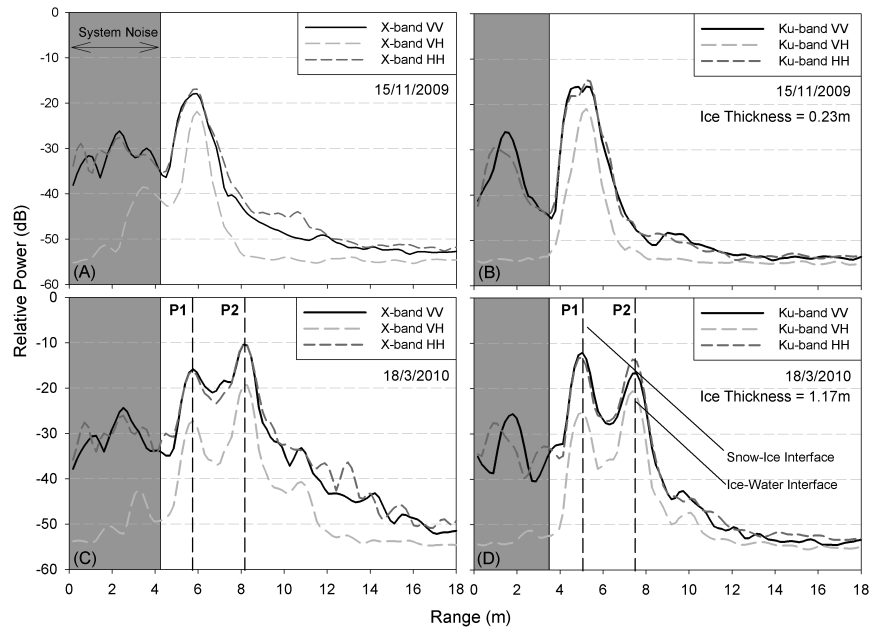

Fig. 5. Range power profiles of UW-Scat at (A) and (C) X- and (B) and (D) Ku-bands for early and late winter season observations at site $3\left(39^{\circ}\right.$ incidence angle). Note that a single defined peak return is noticed in early observations where ice thickness is $0.27 \mathrm{~m}$, and two defined peak returns exist in late season observations when ice thickness is $1.18 \mathrm{~m}$.

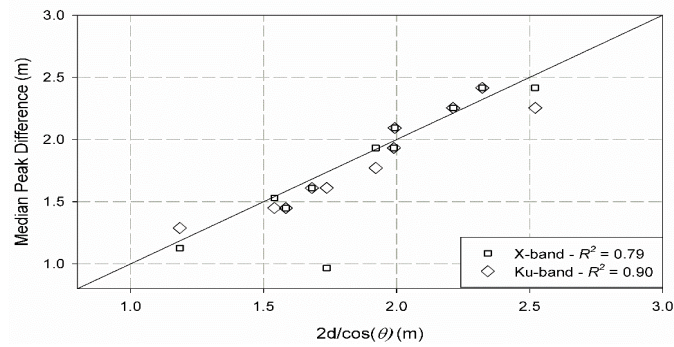

Fig. 6. Verification of the assumption of interactions at the snow-ice and ice-water interfaces represented by Peaks 1 and 2 in range. The Peak $2-$ Peak 1 differences for $\mathrm{X}$ - and Ku-bands tracked the calculated slant range from the refracted incident angle and measured ice thickness with a near 1:1 relationship.

snow-ice interface were greater than that from the ice-water interface.

The travel time to the ice-water interface from the scatterometer increased as ice thickened, allowing for resolution of signal interactions at the snow-ice (P1) and ice-water (P2) interface in the range profiles of both X- and Ku-band observations. The reflected component of backscatter from Peak 2 has typically been hypothesized to be returned to the sensor via double-bounce mechanism caused by tubular bubbles in the ice volume oriented parallel to the direction of ice growth [8], [14]. Assuming double bounce and a consistent refractive index for the ice column, the distance $\left(d_{s}\right)$ traveled by the incident microwave pulse within the ice volume (calculated difference in range of Peaks 1 and 2 shown in Fig. 6) should be equivalent to

$$
d_{s}=\frac{2 d_{\text {meas }}}{\cos \theta}
$$

where $d_{\text {meas }}$ is the measured in situ ice thickness in meters and $\theta$ is the incidence angle observed after adjusting for the refraction caused by the ice $\left(n_{\text {ice }}=1.78\right)$. Fig. 7 shows the median peak difference derived from X- and Ku-bands $\left(21^{\circ}-60^{\circ}\right)$ after adjusting for the speed of light in ice, compared to the calculated slant range using in situ ice thick- 


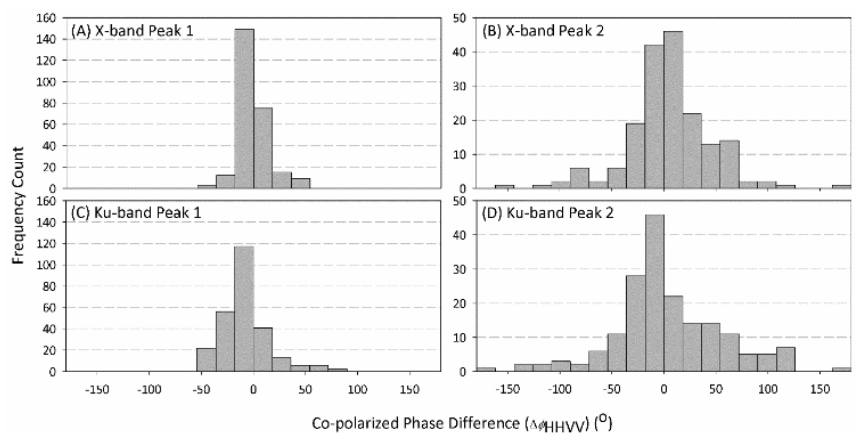

Fig. 7. UW-scat co-polarized phase difference $\left(\Delta \phi_{\mathrm{HHVV}}\right)$ for (A) and (C) Peak 1 and (B) and (D) Peak 2 at all sites and dates on Malcolm Ramsay Lake with the exception of sites where ice is frozen to bed. Observations were collected for (A) and (B) X- and (C) and (D) Ku-bands over a range of $21^{\circ}-60^{\circ}$.

ness measurements for all scatterometer observations observed on Malcolm Ramsay Lake. The derived two-way distance within the ice was nearly equivalent to in situ observations, with coefficient of determination $\left(R^{2}\right)$ of 0.79 and 0.90 for $\mathrm{X}$ - and $\mathrm{Ku}$-bands, respectively, providing evidence that $\mathrm{P} 1$ and P2 returns are interactions near the ice-snow and ice-water interfaces. Deviations from the 1:1 relationship in Fig. 7 could be caused by the influence of the relatively low range resolution $(0.17 \mathrm{~m}$ in ice) of UW-Scat, evidenced by the deviations in ice thickness consistently less than $0.17 \mathrm{~m}$, with an RMSE of 0.05 and $0.047 \mathrm{~m}$ at $\mathrm{X}$ - and $\mathrm{Ku}$-bands, respectively.

Concurrently, the influence of increased ice porosity due to tubular air bubble inclusions could slightly modify the refractive index, whereby $7 \%$ porosity for bubbled columnar ice [16] would cause a reduction in $n_{\text {ice }}(1.74)$ and $\varepsilon_{\text {ice }}^{\prime}(3.04)$, derived through

$$
\varepsilon_{c}^{\prime}=\varepsilon_{\mathrm{ice}}^{\prime}\left(\frac{1+2 p y}{1-p y}\right)
$$

where

$$
y=\frac{1-\varepsilon_{\mathrm{ice}}^{\prime}}{1+2 \varepsilon_{\mathrm{ice}}^{\prime}}
$$

where $p$ is the fraction of air inclusions within the ice [16]. The slight modification in refractive index would result in a difference of derived ice thickness values of $1.6 \%$, or an average of 0.014 and $0.008 \mathrm{~m}$ for $\mathrm{X}$ - and $\mathrm{Ku}$-bands, respectively, well within the RMSE of UW-Scat derived ice thickness values.

2) UW-Scat Backscatter Processing: With the peaks in range determined to correspond to the ice-snow and snow-ice interfaces, it is of interest to obtain the backscatter parameters to investigate the respective intensity of returns with respect to in situ physical parameters. The NRCS $\left(\sigma^{\circ}\right)$ is obtained through

$$
\sigma^{o}=\frac{8 \ln (2) R_{t}^{2} \sigma_{c} \cos \left(\phi_{\text {inc }}\right)}{\pi R_{c}^{4} \theta_{3 \mathrm{~dB}}^{2}}\left(\frac{\dot{\mathrm{P}}_{r}}{\dot{\mathrm{P}}_{r c}}\right)
$$

where $R_{t}$ is the target range, $\sigma_{c}$ is the corner reflector's radar cross section, $\phi_{\text {inc }}$ is the incidence angle, $R_{c}$ is the corner reflector range, $\theta_{3_{\mathrm{dB}}}$ is the observing antenna's one-way halfpower beamwidth, and $\dot{\mathrm{P}}_{r}$ and $\hat{\mathrm{P}}_{r c}$ are the recorded power for the scene and the corner reflector, respectively [55].
Polarimetric parameters are derived using UW-Scat observations to provide context and comparison of those generated from RADARSAT- 2 acquisitions. The co-polarized phase difference $\left(\Delta \phi_{\text {HHVV }}\right)$ is obtained from the average covariance matrix representing the complex scattering amplitudes of data blocks across a scan's azimuth for each incidence angle, represented by (15), with the derivation of $\Delta \phi_{\mathrm{HHVV}}$ using (16). The diagonal terms of the covariance matrix represent returned power at each of the polarizations and are real numbers, whereas the off-diagonal terms provide phase information and are complex numbers [45]

$$
[\mathbf{C}]=\left\langle\left[\begin{array}{llll}
S_{\mathrm{VV}} S_{\mathrm{VV}}^{*} & S_{\mathrm{VV}} S_{\mathrm{VH}}^{*} & S_{\mathrm{VV}} S_{\mathrm{HV}}^{*} & S_{\mathrm{VV}} S_{\mathrm{HH}}^{*} \\
S_{\mathrm{VH}} S_{\mathrm{VV}}^{*} & S_{\mathrm{VH}} S_{\mathrm{VH}}^{*} & S_{\mathrm{VH}} S_{\mathrm{HV}}^{*} & S_{\mathrm{VH}} S_{\mathrm{HHH}}^{*} \\
S_{\mathrm{HV}} S_{\mathrm{VV}}^{*} & S_{\mathrm{HV}} S_{\mathrm{VH}}^{*} & S_{\mathrm{HV}} S_{\mathrm{HV}}^{*} & S_{\mathrm{HV}} S_{\mathrm{HH}}^{*} \\
S_{\mathrm{HH}} S_{\mathrm{VV}}^{*} & S_{\mathrm{HH}} S_{\mathrm{VH}}^{*} & S_{\mathrm{HH}} S_{\mathrm{HV}}^{*} & S_{\mathrm{HH}} S_{\mathrm{HH}}^{*}
\end{array}\right]\right\rangle
$$

$\Delta \phi_{\mathrm{HHVV}}=\tan ^{-1}\left(\frac{\operatorname{Im}\left\langle S_{\mathrm{HH}} S_{\mathrm{VV}}^{*}\right\rangle}{\operatorname{Re}\left\langle S_{\mathrm{HH}} S_{\mathrm{VV}}^{*}\right\rangle}\right)$.

\section{3) UW-Scat $\sigma^{\circ}$ and $\Delta \phi_{\mathrm{HHV}}$ Observations:}

Table IV presents the time series of average $\sigma^{\circ}$ across $30^{\circ}-45^{\circ}$ of $\mathrm{X}$ - and $\mathrm{Ku}$-bands for Peak 1 (interactions near the snow-ice interface), and Peak 2 (interactions near the ice-water interface) for all sites observed on Malcolm Ramsay Lake. X- and Ku-band Peak $1 \mathrm{VV}$ and $\mathrm{HH} \sigma^{\circ}$ is high throughout the observation period $(-13.21$ to $-6.17 \mathrm{~dB})$ at sites 1-3 where thick surface ice layers consisting of high-density spherical microbubbles were present, consistent with [50]. The exception is site 4, where the lowest VV and $\mathrm{HH}$ Peak $1 \sigma^{\circ}$ is observed at both $\mathrm{X}$ - and Ku-bands throughout the observation period, coincident with the thinnest recorded median surface ice types on Malcolm Ramsay Lake $(0.038 \mathrm{~m})$.

There are several instances where Peak $1 \mathrm{Ku}$-band exhibits higher $\sigma^{\circ}$ (bolded) at all polarization combinations (exceptions typically occur early in the data record) at sites 1 and 2 compared to X-band, implying that it is possible that media near the snow-ice interface scatters shorter wavelengths back to the sensor with greater efficiency. Two variables that are identified as potential contributors to $\sigma^{\circ}$ near the snow-ice interface are: 1) the microbubbles in surface ice types (gray or white ice) and 2) the overlying snowpack [40]. These instances also correspond to sites where $\sigma^{\circ}$ at P1 exceeds that of $\mathrm{P} 2$, indicative that there are physical properties at or near the snow-ice interface interacting with the incident signal. When viewing each site individually over the winter season, it is apparent that both $\mathrm{X}$ - and $\mathrm{Ku}$-band $\mathrm{VV} \sigma^{\circ}$ increases are coincident with increased complexity within the snow and ice volumes near the snow-ice interface, consistent with scatterometer measurements of a snow removal experiment in [50]. The first observation for X- and Ku-band P2 is listed as " $n / a$ " because the distance separating P1 and P2 was not sufficient to resolve two distinct returns in range. Ice thickness on November 15, 2009, was approximately $0.2 \mathrm{~m}$, below the 0.4-m operational threshold for UW-Scat reported in [57].

Peak $2 \sigma^{\circ}$ under the traditional hypothesis would interact with the ice volume, specifically observing the double bounce 
TABLE IV

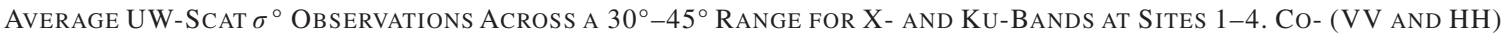
And Cross-Polarization (VH) For Interactions at PEAK 1 (NEAR SNOW-ICE INTERFACE) AND PEAK 2 (ICE-WATER Interface). Bolded Numbers RePresent Where Ku-BAnd P1 $\sigma^{\circ}$ EXCEeds X-BAnd P1

\begin{tabular}{|c|c|c|c|c|c|c|c|c|c|c|c|c|}
\hline \multirow[b]{3}{*}{ Site1 } & \multicolumn{6}{|c|}{ X-band } & \multicolumn{6}{|c|}{ Ku-band } \\
\hline & \multicolumn{3}{|c|}{ Peak 1} & \multicolumn{3}{|c|}{ Peak 2} & \multicolumn{3}{|c|}{ Peak 1} & \multicolumn{3}{|c|}{ Peak 2} \\
\hline & VV & HH & VH & VV & HH & VH & VV & HH & VH & VV & HH & VH \\
\hline $15 / 11 / 09$ & -12.52 & -9.99 & -21.02 & $n / a$ & $\mathrm{n} / \mathrm{a}$ & $n / a$ & -12.60 & -10.76 & -24.51 & $\mathrm{n} / \mathrm{a}$ & $n / a$ & $n / a$ \\
\hline $10 / 01 / 10$ & -10.96 & -11.71 & -25.20 & -10.67 & -8.10 & -17.60 & -7.92 & -8.42 & -20.20 & -11.61 & -10.94 & -19.89 \\
\hline $12 / 02 / 10$ & -8.82 & -10.20 & -24.58 & -8.64 & -7.35 & -18.54 & -7.23 & -7.85 & -18.48 & -11.60 & -9.18 & -18.98 \\
\hline $18 / 3 / 10$ & -8.31 & -9.29 & -23.61 & -16.52 & -14.18 & -24.42 & -6.17 & -6.94 & -17.71 & -24.67 & -23.83 & -30.37 \\
\hline \multicolumn{13}{|l|}{ Site 2} \\
\hline $15 / 11 / 09$ & -12.61 & -20.37 & -12.70 & $\mathrm{n} / \mathrm{a}$ & $\mathrm{n} / \mathrm{a}$ & $\mathrm{n} / \mathrm{a}$ & -7.30 & -6.93 & -19.18 & $n / a$ & $\mathrm{n} / \mathrm{a}$ & $n / a$ \\
\hline $10 / 01 / 10$ & -7.66 & -8.21 & -22.98 & -8.54 & -11.03 & -15.13 & -7.73 & -8.37 & -22.90 & -11.86 & -15.14 & -12.73 \\
\hline $12 / 02 / 10$ & -11.06 & -12.04 & -27.72 & -15.03 & -15.04 & -17.77 & -8.28 & -9.20 & -24.21 & -17.47 & -16.52 & -18.96 \\
\hline $18 / 3 / 10$ & -9.02 & -9.89 & -23.92 & -10.02 & -11.11 & -18.89 & -6.10 & -6.76 & -20.00 & -11.68 & -10.99 & -16.79 \\
\hline \multicolumn{13}{|l|}{ Site 3} \\
\hline $15 / 11 / 09$ & -13.21 & -12.50 & -21.07 & $\mathrm{n} / \mathrm{a}$ & $\mathrm{n} / \mathrm{a}$ & $\mathrm{n} / \mathrm{a}$ & -11.13 & -9.97 & -19.83 & $\mathrm{n} / \mathrm{a}$ & $\mathrm{n} / \mathrm{a}$ & $n / a$ \\
\hline $10 / 01 / 10$ & -9.92 & -10.69 & -27.12 & -7.76 & -6.52 & -14.56 & -8.88 & -9.47 & -24.54 & -5.87 & -4.30 & -14.91 \\
\hline $12 / 02 / 10$ & -9.63 & -10.29 & -26.80 & -5.96 & -4.66 & -16.76 & -7.34 & -7.95 & -24.31 & -7.68 & -4.67 & -14.18 \\
\hline $18 / 3 / 10$ & -10.31 & -11.06 & -26.24 & -5.28 & -4.73 & -14.85 & -7.76 & -8.68 & -20.90 & -8.00 & -7.19 & -14.16 \\
\hline \\
\hline $15 / 11 / 09$ & -20.74 & -21.36 & -34.17 & $\mathrm{n} / \mathrm{a}$ & $\mathrm{n} / \mathrm{a}$ & $\mathrm{n} / \mathrm{a}$ & -16.02 & -14.90 & -33.83 & $\mathrm{n} / \mathrm{a}$ & $\mathrm{n} / \mathrm{a}$ & $\mathrm{n} / \mathrm{a}$ \\
\hline $10 / 01 / 10$ & -8.83 & -9.79 & -23.87 & -9.96 & -10.24 & -21.15 & -8.95 & -9.77 & -21.68 & -12.02 & -11.53 & -26.98 \\
\hline $12 / 02 / 10$ & -9.43 & -10.60 & -26.49 & -14.99 & -14.71 & -29.03 & -10.90 & -10.94 & -23.85 & -10.74 & -9.65 & -27.26 \\
\hline $18 / 3 / 10$ & -12.64 & -12.72 & -26.83 & -9.17 & -8.08 & -23.40 & -9.05 & -8.64 & -21.86 & -8.52 & -6.61 & -20.14 \\
\hline
\end{tabular}

caused by tubular bubbles within the ice and the ice-water interface. The sites observed exhibit increased $\sigma^{\circ}$ from early to late winter season, consistent with the double-bounce hypothesis where high $\sigma^{\circ}$ is observed at $\mathrm{X}$ - and Ku-band Peak 2 for sites with thick bubbled-ice layers (sites 1 and 3), and lower Peak $2 \sigma^{\circ}$ observed at sites where tubular bubble development occurred later in the season (sites 2 and 4). In addition, upon freezing to bed X-and Ku-band Peak $2 \sigma^{\circ}$ at site 1 drops by 8.8 and $12.7 \mathrm{~dB}(\mathrm{VV})$, and 7.3 and $12.6 \mathrm{~dB}(\mathrm{HH})$, respectively, consistent with the removal of the high contrast in permittivity at the ice-water interface.

The Fresnel equations indicate that a dielectric dihedral inducing double bounce will result in a phase change of nearly $180^{\circ}$ between horizontally and vertically polarized radiation. Similarly, the Fresnel equations produce nearly $0^{\circ}$ phase change between $\mathrm{HH}$ and VV when surface bounce occurs. Therefore, the expected HHVV phase difference $\left(\Delta \phi_{\mathrm{HHVV}}\right)$ calculated using (16) for double-bounce interaction near the ice-water interface (Peak 2 for $\mathrm{X}$ - and $\mathrm{Ku}$-band observations) would be nearly $\pm 180^{\circ}$. Fig. 8 shows Peak 2 frequency distribution of $\left(\Delta \phi_{\mathrm{HHVV}}\right)$ for scans at an incidence angle range from $21^{\circ}$ to $60^{\circ}$ for all sites and dates on Malcolm Ramsay Lake. Fewer observations at Peak 2 were available due to thin ice at the beginning of UW-Scat observation period (November 15, 2009). $\Delta \phi_{\mathrm{HHVV}}$ values appear to be centered much closer to $0^{\circ}$ than $\pm 180^{\circ}$ with median values of $-3.77^{\circ}$ and $-12.34^{\circ}$ (Peak 1), and $-4.75^{\circ}$ and $-1.61^{\circ}$ (Peak 2) at $\mathrm{X}$ - and Ku-bands, respectively $(n=60) . \Delta \phi_{\mathrm{HHVV}}$ centered near $0^{\circ}$ indicates that the dominant scattering mechanism near the ice-water interface may be independent of doublebounce scatter, and instead may be caused by scatter at the ice-water interface itself. The spread in $\Delta \phi_{\mathrm{HHVV}}$ outside of $0^{\circ}$ associated with (B) and (D) in Fig. 8 indicates that there are more complex scattering elements present; however, the expected bimodal distribution with peaks located at $\pm 180^{\circ}$ representative of double bounce is not present in UW-Scat observations.

\section{RADARSAT-2 Acquisitions}

A time series of spaceborne C-band (5.4 GHz) RADARSAT2 quad-pol fine beam quad-mode SAR was at multiple incidence angles including FQ1 $\left(17^{\circ}-20^{\circ}\right)$, FQ11 $\left(29^{\circ}-32^{\circ}\right)$, FQ18 $\left(36^{\circ}-69^{\circ}\right)$, and FQ21 $\left(39^{\circ}-42^{\circ}\right)$ coincident with in situ observations, with acquisition dates provided in Table V. All RADARSAT-2 scenes were acquired at ascending pass. Radiometric and geometric calibration was performed using the Sentinel Application Platform version 5.0, multilooking to square pixels $(1 \times 3)$ and producing ground-range $\mathrm{VV}$, $\mathrm{HH}, \mathrm{VH}$, and $\mathrm{HV} \sigma^{\circ}$ and phase at a spatial resolution of $7.26 \times 14.52 \mathrm{~m}$. The co-polarized phase difference $\left(\Delta \phi_{\mathrm{HHVV}}\right)$ was extracted from the multilooked covariance matrix, and the Yamaguchi three-component polarimetric decomposition [60] was performed utilizing the coherency matrix $\left(T_{3}\right)$, producing bands corresponding to surface, double-bounce, and volume interactions. The $\sigma^{\circ}$, phase, and polarimetric decompositions were geocoded to UTM zone $15 \mathrm{~N}$ for spatial analysis. 


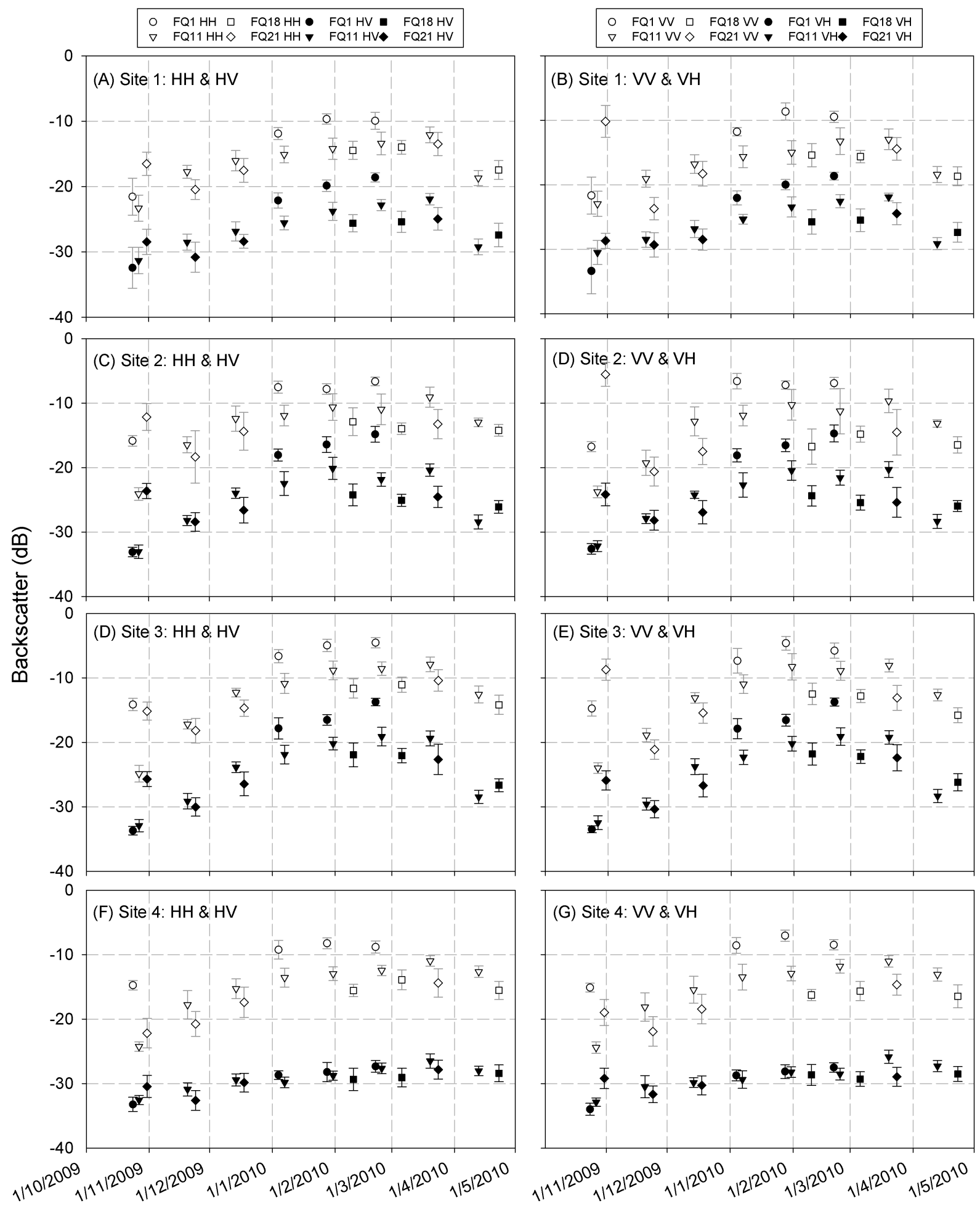

Fig. 8. Winter evolution of median RADARSAT-2 backscatter (dB) and standard deviation (error bars) for all beam modes within a 50-m circular buffer of UW-Scat static sites on Malcolm Ramsay Lake.

Backscatter, phase, and polarimetric decomposition parameters were extracted for a circular buffer of sites $1-4$ with a $50-\mathrm{m}$ radius, and on a lake-wide basis by a negative $50-\mathrm{m}$ buffer of the lake shoreline to ensure the omission of shoreline contamination in the analysis.

The sharp FQ11 $\sigma^{\circ}$ increase of 5-6 dB from October 27, 2009 to November 20, 2009 and again on
December 14, 2009 in both VV and HH polarizations at all sites are coincident with increases in ice thickness confirmed by the in situ SWIP observations, similar to C-band $\mathrm{HH}$ $\sigma^{\circ}$ increases reported in [40] for thin ice (void of tubular bubbles) grown in a laboratory.

SAR $\sigma^{\circ}$ observations at site 1 do not drop as expected when in situ observations deem the site to be frozen to bed on 
TABLE V

RADARS AT-2 Fine BEAM QUAD-Mode ACQUiSitions DuRING 2009-2010 WINTER SEASON, WhICH ARE ALL ACQUIRED IN the Ascending Mode. Average Daily Air Temperature From AN AUTOMATED WEATHER STATION LOCATED ON THE NORTH SHORELINE OF MALCOLM RAMSAY LAKE is Also Provided

\begin{tabular}{ccccc} 
Date & $\begin{array}{c}\text { Incidence } \\
\text { Angles }\left({ }^{\circ}\right)\end{array}$ & $\begin{array}{c}\text { Time } \\
\text { (local) }\end{array}$ & $\begin{array}{c}\text { Beam } \\
\text { Mode }\end{array}$ & $\begin{array}{c}\text { Avg Daily Air } \\
\text { Temperature } \\
\left({ }^{\circ} \mathbf{C}\right)\end{array}$ \\
\hline $24 / 10 / 2009$ & 17.63 & & & -1.17 \\
$4 / 1 / 2010$ & to & $18: 36$ & FQ1 & -29.78 \\
$28 / 1 / 2010$ & 20.48 & & & -25.61 \\
$21 / 2 / 2010$ & & & -15.93 \\
\hline $27 / 10 / 2009$ & & & & -4.19 \\
$20 / 11 / 2009$ & & & & -26.91 \\
$14 / 12 / 2009$ & 29.18 & & & -29.13 \\
$7 / 1 / 2010$ & to & $23: 49$ & FQ11 & -26.27 \\
$31 / 1 / 2010$ & 32.31 & & & -24.94 \\
$24 / 2 / 2010$ & & & & -16.89 \\
$20 / 3 / 2010$ & & & & -0.24 \\
$13 / 4 / 2010$ & & & & -17.88 \\
\hline $10 / 2 / 2010$ & 36.26 & & & -1.34 \\
$6 / 3 / 2010$ & to & $18: 57$ & FQ18 & -4.30 \\
$23 / 4 / 2010$ & 39.24 & & & -4.45 \\
\hline $31 / 10 / 2009$ & 39.45 & & & -10.45 \\
$24 / 11 / 2009$ & to & $19: 01$ & FQ21 & -20.81 \\
$18 / 12 / 2009$ & 42.49 & & & -26.30 \\
$24 / 3 / 2010$ & & & &
\end{tabular}

February 23, 2010, when the auger struck the bottom. The avalanche probe was used to probe the lake bed, and a soft lake bed layer was observed. It is possible that the signal did not drop due to: 1) soft sediment being mixed with water, retaining contrast in permittivity or 2) the spatial variability of areas that are frozen to bed or floating within the 50-m buffer that are not captured by the in situ and UW-Scat observations. An anomalous $\sigma^{\circ}$ departure is also noticed at site 4, where $\mathrm{VH} \sigma^{\circ}$ is much lower than that of other sites, with differences up to $10 \mathrm{~dB}$. The drop in $\mathrm{VH} \sigma^{\circ}$ is observed to be part of a larger feature on the lake where $\sigma^{\circ}$ observations approach the noise floor $(-35.5 \mathrm{~dB}$ for FQ11 mid-swath) [Fig. 10(C)]. The feature persists for the duration of the observation period for all beam modes (FQ1-FQ 21), indicating the potential that $\mathrm{VH} \sigma^{\circ}$ could be insensitive to tubular bubble inclusions observed in the ice core. Site 4 exhibits thinner surface ice types than sites 2 and 3, indicating that the high densities of spherical bubbles in white or gray ice at sites 2 and 3 are potentially depolarizing to incident microwaves. It is unlikely that this is due to increased moisture (flooding of ice) because the feature is persistent throughout the year, was not documented in situ, and temperatures were consistently below freezing.

Median co-polarized phase differences for the 50-m buffer of sites 1-4 and lake-wide pure-ice pixels indicate a dominant pattern whereby $\Delta \phi_{\mathrm{HHVV}}$ is centered at approximately $0^{\circ}$ for the majority of observations, with a maximum median departure of $-15.11^{\circ}$ observed at site 4 on November 24, 2009 $(n=34)$. When observed at the lake-wide scale, the median $\Delta \phi_{\mathrm{HHVV}}$ is centered at approximately $0^{\circ}$ with an average deviation of $0.95^{\circ}$ across the Radarsat beam modes. The dependence of $\Delta \phi_{\mathrm{HHVV}}$ on incidence angle is also observed

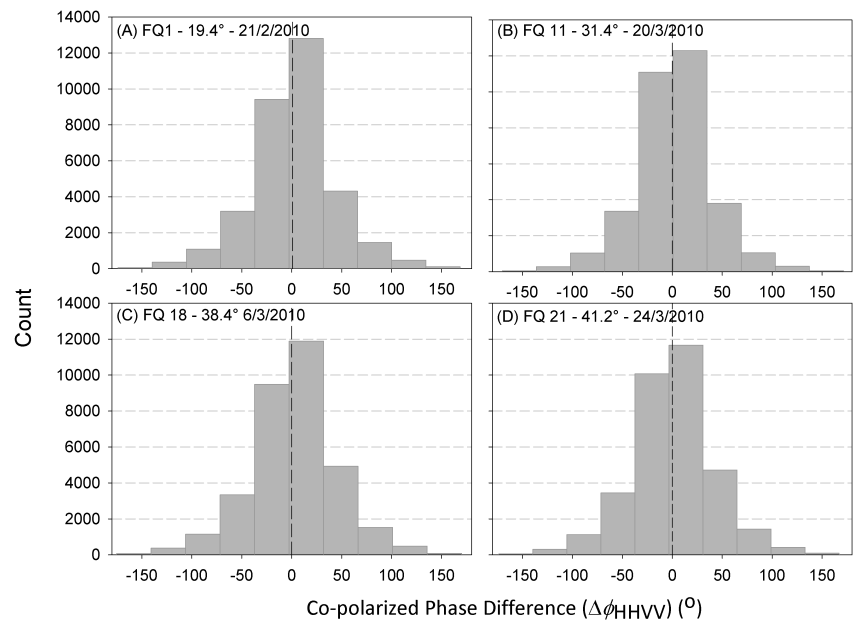

Fig. 9. Lake-wide $\Delta \boldsymbol{\phi}_{H} \boldsymbol{H} \boldsymbol{V} \boldsymbol{V}$ for late-winter RADARSAT-2 acquisitions across an incidence angle range of $19.4^{\circ}-41.2^{\circ}$ using all beam modes during a four-week period from February 21, 2010-March 24, 2010. The last coldperiod acquisition is shown to illustrate observations obtained at maximum ice thickness for each beam mode.

using multiple beam modes over an incidence angle range of $19.4^{\circ}-41.4^{\circ}$. These acquisitions were acquired within a one month period from February 21, 2010 to March 24, 2010, when ice growth is minimal (e.g., observed ice growth was $0.03 \mathrm{~m}$ at site 3 over that time) (Fig. 9). The frequency distribution of $\Delta \phi_{\mathrm{HHVV}}$ across the incidence angle range is consistently unimodal and centered at approximately $0^{\circ}$, with median $\Delta \phi_{\mathrm{HHVV}}$ of $2.96^{\circ}, 0.65^{\circ}, 6.5^{\circ}$, and $0.81^{\circ}$ at $\mathrm{FQ} 1$, FQ11, FQ18, and FQ 21, respectively.

\section{RADARSAT-2 Polarimetric Decomposition}

RADARSAT-2 polarimetric decomposition parameters are produced using the Yamaguchi three-component Decomposition. The relative proportion of odd bounce (surface), even bounce (double bounce), and volume scatter to total $\sigma^{\circ}$ is shown in Fig. 10(D)-(F). The median values of the pixels within the 50-m footprint are provided in Table VI in logarithmic scale $(\mathrm{dB}$ ), with the range of values at sites 3 and 4 (those with contrasting snow/ice regimes) in Fig. 9. Surface bounce is identified as the dominant scattering mechanism contributing to overall $\sigma^{\circ}$ across all static sites and is on average 10 and 14 times greater than the volume scatter and doublebounce components, respectively. Volume scatter is identified as the second largest $\sigma^{\circ}$ source with the exception of site 4 , where low cross-polarized $\sigma^{\circ}$ is observed. Doublebounce scattering mechanism is consistently identified as the smallest $\sigma^{\circ}$ source, even at site 3, where dense tubular bubbles were observed to be included into the ice volume as early as January 9, 2010 (according to ice core records). At site 4, the volume scatter decomposition parameter is the lowest $\sigma^{\circ}$ contributor, which is spatially coincident with the thinnest layers of surface ice types containing spherical bubbles $(0.05 \mathrm{~m})$ compared to sites 2 or $3(0.11 \mathrm{~m})$.

The identification of surface bounce as the dominant contributor to backscatter is also prevalent when viewed at the lake-wide scale (Fig. 11). The RADARSAT $\sigma^{\circ}$ increase 


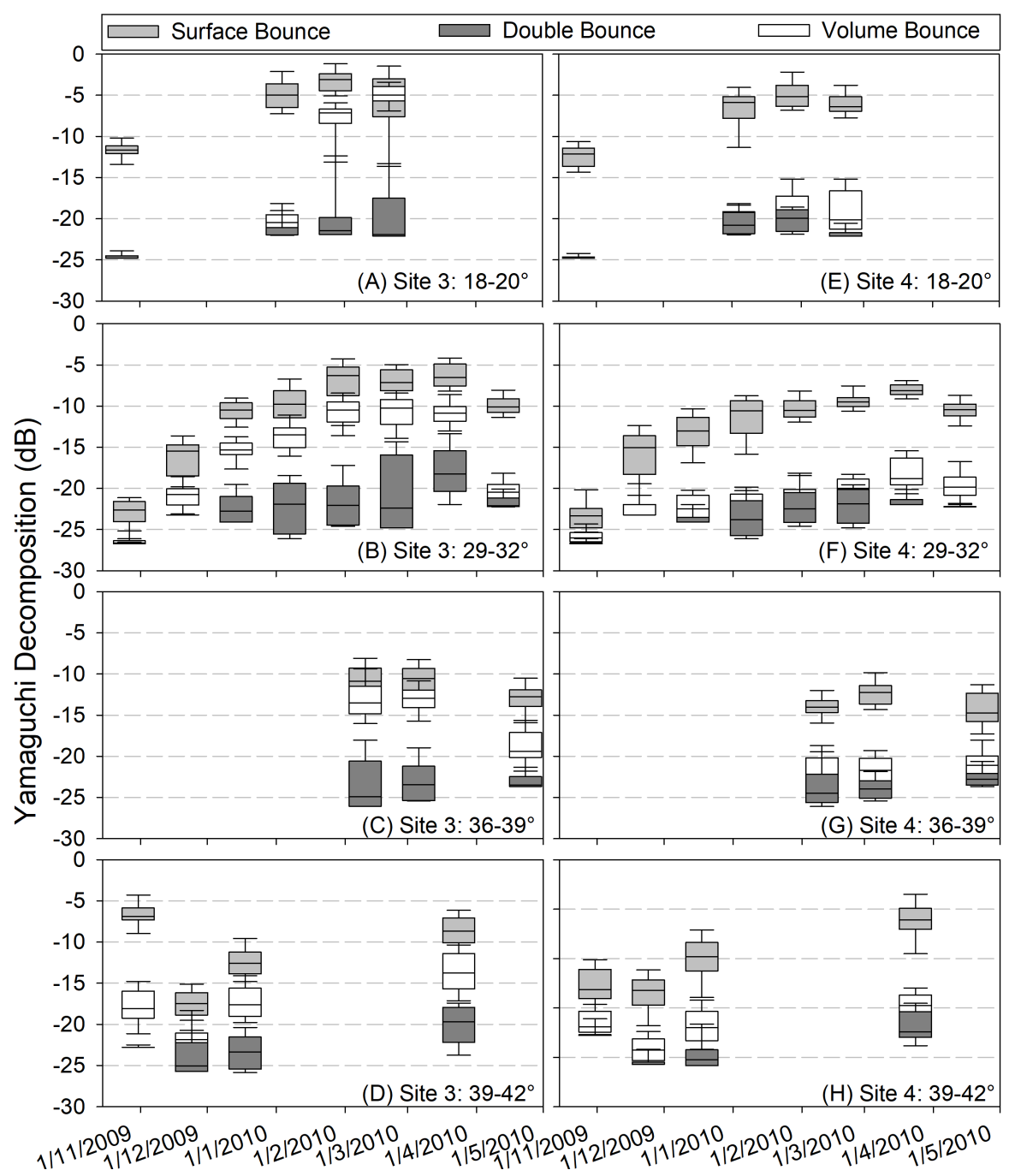

Fig. 10. Time series and distribution $(n=35)$ of RADARSAT-2-derived Yamaguchi three-component decomposition parameters for all beam modes acquired at sites $3(\mathrm{~A}-\mathrm{D})$ and $4(\mathrm{E}-\mathrm{H})$. Surface bounce is consistently identified as the dominant component across all incidence angles.

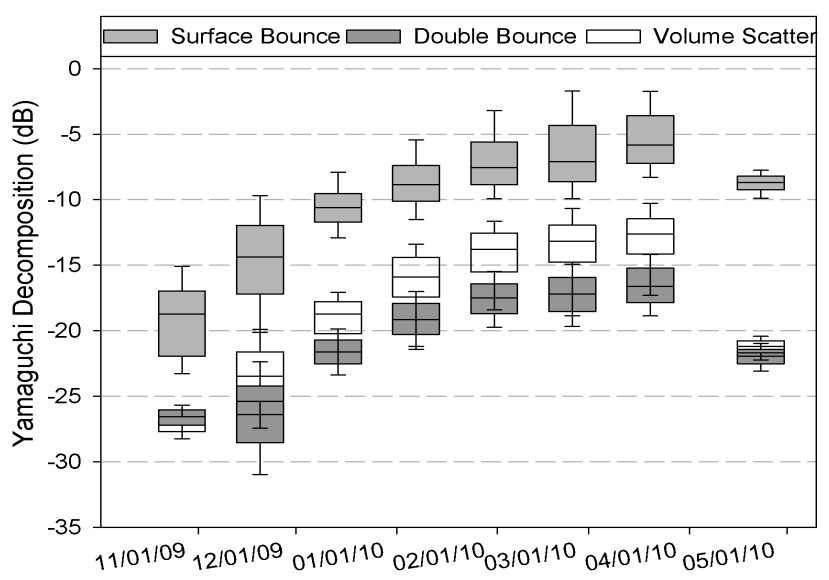

Fig. 11. Time series and distribution of RADARSAT-2-derived Yamaguchi three-component decomposition parameters at lake-wide scale acquired using FQ11 $\left(29^{\circ}-32^{\circ}\right)$. Surface bounce is the dominant component of observed $\sigma^{\circ}$, followed by volume scatter.

noticed in Fig. 13 at each static site prior to the development of tubular bubbles in the ice volume is corroborated by the polarimetric decomposition, indicating that double bounce caused by tubular bubble content is not the dominant scat- tering mechanism, consistent with [24], [25]. Fig. 12 also indicates that the decomposed mechanisms controlling lakewide backscatter increase in prevalence during the observation period. Increases in surface, volume, and double-bounce components could be related to increases in the thickness of the ice medium; however, the intensities are likely controlled by physical snow and ice parameters (e.g., increase in surface roughness at the ice-water interface throughout the season resulting in high surface-bounce interactions, consistent with [24]). When observing RADARSAT- $2 \sigma^{\circ}$ at a lake-wide scale, it is likely that areas of grounded ice are included in the observation later in the winter season, which would increase $\sigma^{\circ}$ variability for months with thick ice (March-April) due to areas of ice that are frozen to the lake bed, as the high contrast in permittivity at the ice-water interface is removed.

\section{Discussion}

The combination of UW-Scat/RADARSAT-2 co-polarized phase differences and polarimetric decomposition parameters provide evidence contrary to the traditional hypothesis 
TABLE VI

Time Series of Median $(n=35)$ Yamaguchi Three-Component Decomposition Parameters Derived From RADARS AT-2 AcQuisitions For UW-Scat Sites 1-4: Odd (Surface) Bounce, Even (Double) Bounce, and Volume Scatter (dB). The Dominant Scattering MeChanism is Bolded, AND THE SECond-Most Dominant is ITALICIZEd

\begin{tabular}{|c|c|c|c|c|c|c|c|c|c|c|c|c|c|}
\hline \multirow[b]{2}{*}{ Date } & \multirow{2}{*}{$\begin{array}{c}\text { Inc } \\
\text { Angle }\end{array}$} & \multicolumn{4}{|c|}{ Odd (dB) } & \multicolumn{4}{|c|}{ Double-bounce (dB) } & \multicolumn{4}{|c|}{ Volume (dB) } \\
\hline & & 1 & 2 & 3 & 4 & 1 & 2 & 3 & 4 & 1 & 2 & 3 & 4 \\
\hline $24 / 10 / 2009$ & & -21.14 & -13.51 & -11.67 & -12.15 & N/A & N/A & N/A & N/A & N/A & N/A & N/A & N/A \\
\hline $4 / 1 / 2010$ & $\begin{array}{l}17^{\circ} \\
\text { to }\end{array}$ & -10.28 & -10.38 & -4.97 & -5.88 & -21.94 & -22.23 & -21.94 & -20.77 & -13.90 & -20.42 & -20.47 & -20.67 \\
\hline $28 / 1 / 2010$ & $20^{\circ}$ & -7.96 & -8.49 & -3.12 & -5.17 & -19.21 & -20.83 & -21.44 & -19.93 & -12.58 & -6.82 & -7.15 & -19.21 \\
\hline $21 / 2 / 1010$ & & -9.92 & -7.99 & -4.58 & -6.42 & -21.77 & -21.57 & -21.91 & -22.13 & -9.92 & -6.80 & -5.00 & -20.16 \\
\hline $27 / 10 / 2009$ & & -22.72 & -22.80 & -22.63 & -23.31 & -26.73 & -26.73 & -26.73 & -26.73 & -24.78 & -26.29 & -26.65 & -26.02 \\
\hline $20 / 11 / 2009$ & & -17.19 & -15.01 & -15.47 & -15.06 & -23.21 & -23.21 & -23.21 & -23.21 & -20.29 & -20.51 & -20.74 & -23.21 \\
\hline $14 / 12 / 2009$ & & -15.25 & -12.64 & -10.47 & -13.04 & -24.11 & -23.36 & -22.75 & -24.11 & -18.80 & -15.74 & -15.34 & -22.47 \\
\hline $7 / 1 / 2010$ & $\begin{array}{l}29^{\circ} \\
\text { to }\end{array}$ & -15.29 & -10.80 & -9.76 & -10.57 & -25.75 & -23.39 & -21.93 & -23.78 & -16.77 & -14.09 & -13.50 & -21.62 \\
\hline $31 / 1 / 2010$ & $32^{\circ}$ & -14.80 & -9.26 & -6.29 & -10.51 & -23.36 & -21.46 & -22.08 & -22.47 & -15.65 & -12.53 & -10.50 & -21.20 \\
\hline $24 / 2 / 2010$ & & -12.45 & -10.92 & -7.12 & -9.50 & -24.04 & -20.35 & -22.37 & -21.87 & -13.49 & -13.47 & -10.24 & -19.98 \\
\hline $30 / 3 / 2010$ & & -11.44 & -8.47 & -6.54 & -8.13 & -21.97 & -19.84 & -18.26 & -21.99 & -13.17 & -11.18 & -10.86 & -18.82 \\
\hline $23 / 4 / 2010$ & & -16.44 & -10.38 & -10.08 & -10.44 & -22.23 & -22.23 & -22.10 & -22.23 & -21.45 & -20.42 & -20.47 & -19.85 \\
\hline $10 / 2 / 2010$ & $36^{\circ}$ & -15.13 & -11.42 & -10.88 & -14.05 & -25.35 & -23.15 & -24.90 & -24.48 & -18.22 & -15.83 & -13.51 & -23.25 \\
\hline $6 / 3 / 2010$ & $\begin{array}{l}\text { To } \\
39^{\circ}\end{array}$ & -13.81 & -12.40 & -10.54 & -12.25 & -24.36 & -23.92 & -23.44 & -23.99 & -17.44 & -16.30 & -12.96 & -21.71 \\
\hline $23 / 4 / 2010$ & & -17.26 & -14.23 & -12.77 & -14.74 & -23.57 & -23.39 & -23.51 & -22.79 & -19.14 & -18.25 & -19.41 & -21.09 \\
\hline $31 / 10 / 2009$ & & -6.27 & -3.98 & -6.89 & -18.16 & -22.79 & -22.79 & -22.79 & -22.79 & -20.36 & -16.13 & -18.10 & -21.92 \\
\hline 24/11/2009 & $\begin{array}{l}39^{\circ} \\
\text { To }\end{array}$ & -19.91 & -17.44 & -17.47 & -18.23 & -25.72 & -24.48 & -25.03 & -25.72 & -22.78 & -20.24 & -21.83 & -24.28 \\
\hline $18 / 12 / 2009$ & $42^{\circ}$ & -18.12 & -14.41 & -12.60 & -14.81 & -25.83 & -25.18 & -23.36 & -25.24 & -20.76 & -16.97 & -17.64 & -22.01 \\
\hline $24 / 3 / 2010$ & & -12.69 & -11.56 & -8.69 & -11.08 & -22.76 & -23.28 & -19.69 & -22.42 & -17.47 & -14.56 & -13.74 & -19.77 \\
\hline
\end{tabular}

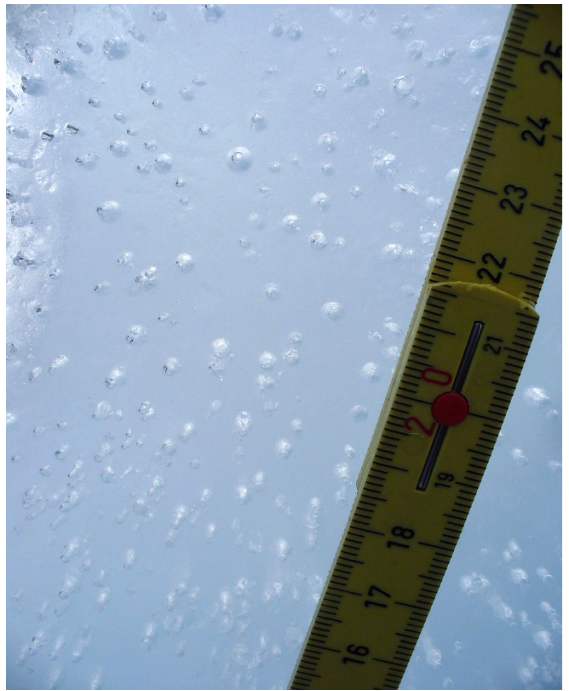

Fig. 12. Tubular bubble inclusions with terminus breaching the ice-water interface of the underside of an extracted core at site 4 on Malcolm Ramsay Lake (April 16, 2010). Multiple bubble termini diameters are observed at sizes of 4 to $6 \mathrm{~mm}$.

of double-bounce scatter being the dominant component in observed backscatter [11]-[14], [21], [61]. The co-polarized phase difference equaling near-zero degrees for both UW-Scat
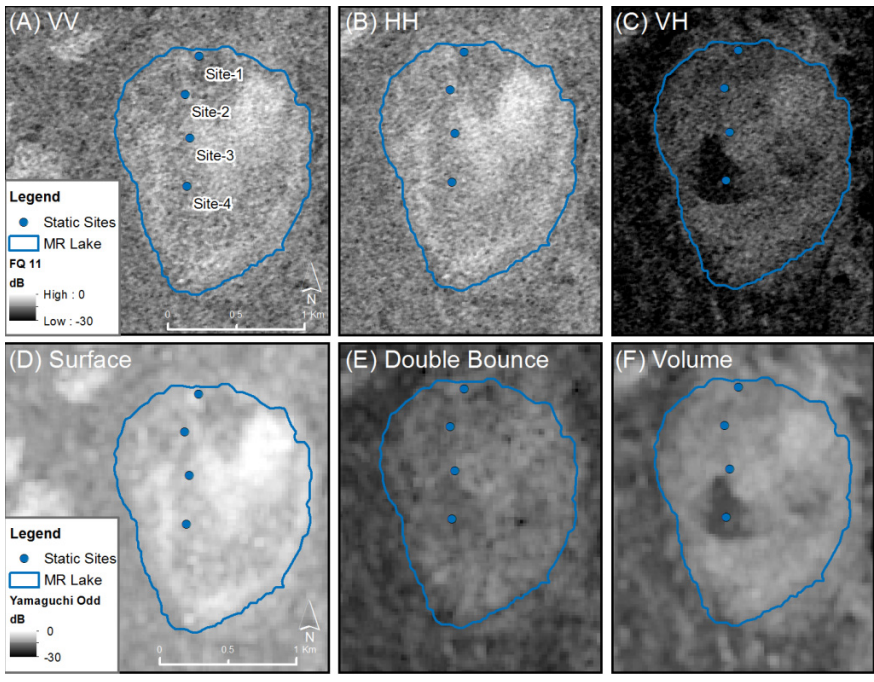

Fig. 13. RADARSAT-2 $\sigma^{\circ}$ (A) VV, (B) HH, and (C) VH and Yamaguchi three-component decomposition detailing the contribution from (D) surface scatter, (E) double bounce, and (F) volume scatter for Malcolm Ramsay Lake during peak ice thickness conditions prior to melt (March 20, 2010). RADARSAT-2 Data and Product MacDonald, Dettwiler and Associates Ltd. (2010)_All Rights Reserved.

Peak 2 and RADARSAT- 2 observations indicates that it is unlikely that double-bounce scatter is the primary scattering 


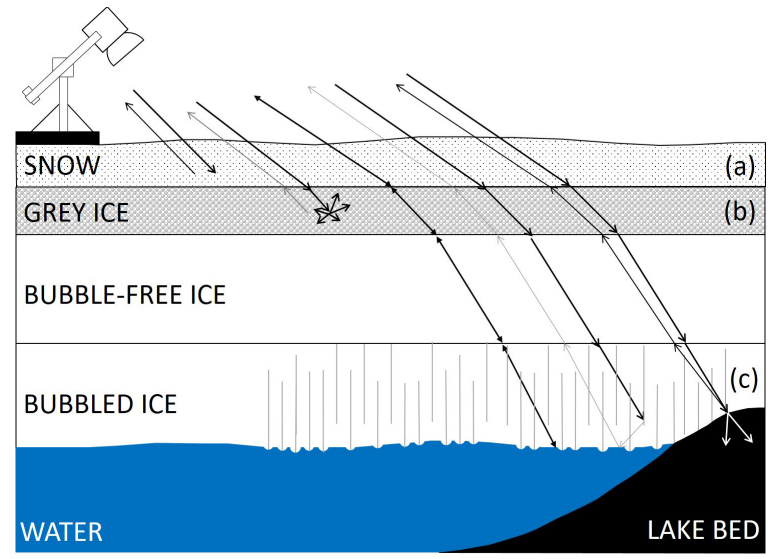

Fig. 14. Updated contribution of scattering mechanisms to total backscatter as determined by Yamaguchi three-component decomposition. The surfacebounce component is the dominant contribution for bubbled freshwater ice. Double-bounce and volume scatter contributions increased throughout the season but were several magnitudes lower than surface bounce.

mechanism in lake ice, but rather a surface bounce from the ice-water interface.

Similarly, increases in the surface-bounce component observed in the polarimetric decomposition time series indicate that the scattering mechanism is likely caused by interaction with an increasingly rough surface with contrasting dielectric properties, such as the ice-water interface, supported by UW-Scat P2 observations. The intensity of all contributions increases throughout the season; however, the surface-bounce component consistently exhibited the greatest intensity and proportion of overall backscatter. The evolution of RADARSAT- 2 acquisitions from freeze-onset to the melt season characterizes the scattering contribution of surface, double-bounce, and volume scattering elements throughout the evolution of the ice cover on Malcolm Ramsay Lake. This paper is the first to demonstrate that the surface bounce component was observed to be the dominant source to overall backscatter at all instances throughout the winter season, including prior to the development and inclusion of tubular bubbles into the ice volume, using in situ observations as ground truth. In addition, once tubular bubbles were observed in the ice column, the polarimetric decomposition indicated that double-bounce contributions to overall backscatter do not eclipse the contribution from surface scatter at the ice-water interface.

Initially, observations by UW-Scat appeared to provide a time series of backscatter similar to previous studies that hypothesize that the dominant scattering mechanism is the result of double-bounce interaction with tubular bubbles near the ice-water interface due to the difference in distance to Peaks 1 and 2 ranges being equivalent to the range to the snow-ice and ice-water interfaces. However, the two-way distance for double bounce is equal to that of single-bounce off of a rough surface at the ice-water interface

With the evidence provided by co-polarized phase difference and polarimetric decomposition derived from UW-Scat and RADARSAT-2, indicating that surface bounce is the dominant scattering mechanism, the cause of surface roughness at the ice-water interface must be addressed. Ice thickness is modified by the insulating properties of the surface snowpack. Snow redistribution and drifting is prevalent and quite variable on Malcolm Ramsay Lake, likely resulting in large-scale roughness at the ice-water interface at scales much larger than the incident wavelength, but sufficient to modify the relative incidence angle of the signal to appear closer to normal/perpendicular of the ice-water interface.

An additional contributing factor to surface roughness could also be the presence of tubular bubbles terminating at the icewater interface. Observed bubble density in the ice volume increased with ice thickness, with the spherical portion of the terminus near or at the ice-water interface. The terminus also increases in diameter deeper in the ice volume, with diameters of 1 and $5 \mathrm{~mm}$ at upper and lower depths, respectively (incomplete bubble protrusion at site 4 observed at the ice underside of an extracted ice core in Fig. 14). Bubbles that have not been sealed within ice after ice have encroached beyond the bubble terminus protrude out the bottom of the ice-water interface, similar to observations conducted by Inada et al. [62]. The surface roughness is modified by the bubble protrusion as there is a low contrast in permittivity maintained from the ice to the bubble. Laboratory measurements of bubbles incorporated into the ice volume indicate that as the ice growth rate slows as ice thickens, the diameter of columnar bubbles inclusions increases [63], [64]. The shape of the terminus of tubular bubbles is typically described as "egg shaped," resulting in the size of bubble terminus protruding from the ice as a semisphere that is at minimum equivalent to the bubble diameter within the ice. In situ observation of bubble diameter at the ice underside in this study of up to $5 \mathrm{~mm}$, providing evidence that bubble protrusions at the ice underside could be up to $5 \mathrm{~mm}$, provides height deviations sufficient to eclipse the Fraunhofer roughness criteria for the frequencies observed in Table I.

Furthermore, there appears to be a slight preference to $\mathrm{HH}$ scattering in UW-Scat when observing P2 (interaction near ice-water interface) and RADARSAT-2 acquisitions, with co-polarization ratio $\left(\sigma_{\mathrm{HH}} / \sigma_{\mathrm{VV}}\right)$ near unity. As roughness increases, the co-polarization ratio will revert to 1 ; however, the dihedral regime exists above 1 (65). The slight preference to $\mathrm{HH} \sigma^{\circ}$ at $\mathrm{C}-, \mathrm{X}-$, and $\mathrm{Ku}$-bands indicates that $\mathrm{HH}$ could exhibit increased sensitivity to roughness at the ice-water interface, which is not currently possible to explicitly quantify from in situ observations due to the recommended spacing of ice thickness observations with respect to the size of incident wavelengths. Further research needs to be performed to provide a better characterization and quantification of the RMS surface roughness and the associated correlation length at the ice-water interface, with a focus on also preserving the orientation and position of bubbles directly beneath the ice to identify its contribution to overall interface roughness.

The observations of this paper indicate that the surfacebounce component is the dominant backscatter return, and based on the ranges of UW-Scat observations, the ice-water interface is the source, contrasting the double-bounce hypothesis of [13] and [21]. There were some instances where surface 
ice types increased backscatter for P1 to levels higher than P2; however, the $\Delta \phi_{\mathrm{HHVV}}$ indicates that P2 backscatter was still the result of surface interactions. The mechanism by which the roughness of ice-water interface is modified is not explicitly known, but is hypothesized to be the result of faceting of the surface, and/or the terminus of bubble inclusions extending out from the interface. Based on the Fresnel reflection equations, a possible mechanism that could provide single bounce at the ice-water interface would be the increase in surface roughness or larger scale orientation of facets at the icewater interface to produce a confluence of angles that would produce local mirror-like target geometry. In this fashion, this research corroborates that of [24] in determining that surface bounce not double bounce is the primary source of backscatter in lake ice evidenced by the co-polarized phase difference, polarimetric decomposition, and co-polarized ratio. An updated version of scattering mechanisms in lake ice is shown in Fig. 14, whereby the double-bounce and volume scatter contributions to $\sigma^{\circ}$ observed at the sensor are secondary to surface bounce.

\section{CONCLUSION}

The longstanding hypothesis suggesting $\sigma^{\circ}$ increases observed over a winter time series are the result of forward double-bounce scatter caused by tubular bubble inclusions near the ice-water interface was tested using fully polarimetric scatterometer and SAR observations. Observations from the RADARSAT- 2 time series indicates that $\sigma^{\circ}$ increases were dominantly returned from the ice-water interface before the inclusion of tubular bubbles into the ice volume, suggesting the existence of an alternate scattering regime. The surface scatter component increased as bubbles were incorporated into the ice volume at the ice-water interface, further adding to the surface roughness. This is the first study to hypothesize the sensitivity of $\mathrm{C}$ - through $\mathrm{Ku}$-band to the presence of bubbles resting at the underside of the ice forming a synthetic surface roughness at the ice-water interface.

The phase information from both UW-Scat and RADARSAT-2 indicates that the co-polarized difference is centered at approximately $0^{\circ}$. Even when observed on a lake-wide scale using RADARSAT-2, the maximum departure of median $\Delta \phi_{\mathrm{HHVV}}$ is less than $7^{\circ}$. In addition, Yamaguchi three-component polarimetric decomposition results identified the dominant $\sigma^{\circ}$ component as single-bounce off the icewater interface. It is hypothesized that the surface roughness at the ice-water interface combined with roughness created at the terminus of bubbles at the ice-water interface of thick ice cover may result in an increase of the surface-bounce component, indicating that co-polarized ( $\mathrm{HH}$ or $\mathrm{VV}) \sigma^{\circ}$ increases may still provide a proxy measure for ice with tubular bubbles versus clear ice in the lower depths of the ice volume, while cross-polarized ( $\mathrm{HV}$ or $\mathrm{VH}$ ) indicates interaction with spherical bubbles in the surface ice layers. These results suggest that since the dominant source of backscatter is surface interaction with the ice-water interface that a possibility exists to utilize repeat-pass SAR imagery to calculate interferometric height deviations and potentially retrieve ice thickness measurements remotely. This is currently an avenue of future research.

\section{ACKNOWLEDGMENT}

Logistics for field data collection was provided by the Churchill Northern Studies Center, Churchill, MB, Canada. The authors would like to thank all those who assisted in field data collection, notably A. Silis, C. Derksen, A. Langlois, K. Kang, J. Oldham, A. Casey, B. Monpetit, and A. Royer. UW-Scat was developed and manufactured by J. Mead at ProSensing Inc., Amherst, MA, USA, with funding from the Canadian Foundation for Innovation and the Ontario Ministry of Research and Innovation to C. Duguay and R. Kelly.

\section{REFERENCES}

[1] L. C. Brown and C. R. Duguay, "The response and role of ice cover in lake-climate interactions," Prog. Phys. Geogr., vol. 34, no. 5, pp. 671-704, Jul. 2010.

[2] W. R. Rouse, P. D. Blanken, C. R. Duguay, C. J. Oswald, and W. M. Schertzer, "Climate-lake interactions," in Cold Region Atmospheric and Hydrologic Studies. The Mackenzie GEWEX Experience, M. K. Woo, Ed. Berlin, Germany: Springer, 2008, ch. 8, pp. 139-160.

[3] H. K. Pour, L. Rontu, C. R. Duguay, K. Eerola, and E. Kourzeneva, "Impact of satellite-based lake surface observations on the initial state of HIRLAM. Part II: Analysis of lake surface temperature and ice cover," Tellus A, Dyn. Meteorol. Oceanogr., vol. 66, Sep. 2014, Art. no. 21395.

[4] J. Overland et al., "Air temperature," in Arctic Report Card, M. O. Jeffries, J. Richter-Menge, and J. E. Overland, Eds. [Online]. Available: http://www.arctic.noaa.gov/reportcard

[5] C. R. Duguay, T. D. Prowse, B. R. Bonsal, R. D. Brown, M. P. Lacroix, and P. Ménard, "Recent trends in Canadian lake ice cover," Hydrol. Process., vol. 20, no. 4, pp. 781-801, Mar. 2006.

[6] S. E. L. Howell, L. C. Brown, K.-K. Kang, and C. R. Duguay, "Variability in ice phenology on Great Bear Lake and Great Slave Lake, Northwest Territories, Canada, from SeaWinds/QuikSCAT: 2000-2006,' Remote Sens. Environ., vol. 113, no. 4, pp. 816-834, 2009.

[7] M. O. Jeffries, K. Morris, and G. E. Liston, "A method to determine lake depth and water availability on the North Slope of Alaska with spaceborne imaging radar and numerical ice growth modelling," Arctic, vol. 49, no. 4, pp. 367-374, 1996.

[8] C. R. Duguay and P. M. Lafleur, "Determining depth and ice thickness of shallow sub-Arctic lakes using space-borne optical and SAR data," Int. J. Remote Sens., vol. 24, no. 3, pp. 475-489, 2003.

[9] K.-K. Kang, C. R. Duguay, S. E. L. Howell, C. P. Derksen, and R. E. J. Kelly, "Sensitivity of AMSR-E brightness temperatures to the seasonal evolution of lake ice thickness," IEEE Geosci. Remote Sens. Lett., vol. 7, no. 4, pp. 751-755, Oct. 2010.

[10] K.-K. Kang, C. R. Duguay, J. Lemmetyinen, and Y. Gel, "Estimation of ice thickness on large northern lakes from AMSR-E brightness temperature measurements," Remote Sens. Environ., vol. 150, pp. 1-19, Jul. 2014.

[11] P. Sellmann, W. F. Weeks, and W. J. Campbell, "Use of side-looking airborne radar to determine lake depth on the Alaskan North Slope," U.S Army Cold Regions Res. Eng. Lab, Hanover, NH, USA, Tech. Rep. 230, 1975 , p. 6.

[12] C. Elachi, M. L. Bryan, and W. F. Weeks, "Imaging radar observations of frozen Arctic lakes," Remote Sens. Environ., vol. 5, pp. 169-175, Dec. 1976.

[13] W. F. Weeks, A. J. Gow, and R. J. Schertler, "Ground-truth observations of ice-covered North Slope lakes imaged by radar," Cold Regions Res. Eng. Lab, Hanover, NH, USA, Tech. Rep. CRREL-81-19, 1981.

[14] M. O. Jeffries and K. Morris, "Structural and stratigraphie features and ERS 1 synthetic aperture radar backscatter characteristics of ice growing on shallow lakes in NW Alaska, winter 1991-1992," J. Geophys. Res., vol. 99, no. C11, pp. 22459-22471, 1994.

[15] C. M. Surdu, C. R. Duguay, L. C. Brown, and D. F. Prieto, "Response of ice cover on shallow lakes of the North Slope of Alaska to contemporary climate conditions (1950-2011): Radar remote-sensing and numerical modeling data analysis," Cryosphere, vol. 8, no. 1, pp. 167-180, 2014. 
[16] I. Gherboudj, M. Bernier, and R. Leconte, "A backscatter modeling for river ice: Analysis and numerical results," IEEE Trans. Geosci. Remote Sens., vol. 48, no. 4, pp. 1788-1798, Apr. 2010.

[17] T. Matsuoka et al., "A backscattering model for bubbles in lake ice and comparisons with satellite and airborne SAR data," in Proc. IEEE Int. Geosci. Remote Sens. Symp. (IGARSS), Jun./Jul. 1999, pp. 107-109.

[18] H. Wakabayashi, M. O. Jeffries, and W. F. Weeks, "C-band backscatter variation and modeling for lake ice in Northern Alaska," J. Jpn. Remote Sens., vol. 18, no. 220, pp. 220-229, 1994.

[19] J.-S. Lee and E. Pottier, Polarimetric Radar Imaging: From Basics to Applications. Boca Raton, FL, USA: CRC Press, 2009.

[20] R. Leconte and P. D. Klassen, "Lake and river ice investigations in northern Manitoba using airborne SAR imagery," Arctic, vol. 44, no. 5, pp. 153-163, 1991.

[21] C. R. Duguay, T. J. Pultz, P. M. Lafleur, and D. Drai, "RADARSAT backscatter characteristics of ice growing on shallow sub-Arctic lakes, Churchill, Manitoba, Canada," Hydrol. Process., vol. 16, no. 8 , pp. 1631-1644, Jun. 2002.

[22] M. Engram, K. W. Anthony, F. J. Meyer, and G. Grosse, "Synthetic aperture radar (SAR) backscatter response from methane ebullition bubbles trapped by thermokarst lake ice," Can. J. Remote Sens., vol. 38, no. 6, pp. 667-682, 2012.

[23] M. Engram, K. W. Anthony, F. J. Meyer, and G. Grosse, "Characterization of L-band synthetic aperture radar (SAR) backscatter from floating and grounded thermokarst lake ice in Arctic Alaska," Cryosphere, vol. 7, no. 6, pp. 1741-1752, 2013.

[24] D. K. Atwood, G. E. Gunn, C. Roussi, J. Wu, C. R. Duguay, and K. Sarabandi, "Microwave backscatter from Arctic lake ice and polarimetric implications," IEEE Trans. Geosci. Remote Sens., vol. 53, no. 11, pp. 5972-5982, Nov. 2015.

[25] J. Wu, D. Atwood, and K. Sarabandi, "Scattering phenomenology of Arctic lake ice," in Proc. Geosci. Remote Sens. Symp. (IGARSS), 2016, pp. 3668-3671.

[26] Y. Yamaguchi, Y. Yajima, and H. Yamada, "A four-component decomposition of POLSAR images based on the coherency matrix," IEEE Geosci. Remote Sens. Lett., vol. 3, no. 3, pp. 292-296, Jul. 2006.

[27] F. T. Ulaby, R. K. Moore, and A. K. Fung, Microwave Remote Sensing: Active and Passive, Radar Remote Sensing and Surface Scattering and Emission Theory, vol. 2. Norwood, MA, USA: Addison-Wesley, 1986.

[28] T. Meissner and F. J. Wentz, "The complex dielectric constant of pure and sea water from microwave satellite observations," IEEE Trans. Geosci. Remote Sens., vol. 42, no. 9, pp. 1836-1849, Sep. 2004.

[29] C. Mätzler and U. Wegmuller, "Dielectric properties of fresh-water ice at microwave frequencies," J. Phys. D, Appl. Phys., vol. 20, no. 12, pp. 1623-1630, 1987.

[30] H.-P. Marshall and C. R. Duguay, "Backscatter measurements of ice and snow on Toolik Lake, Alaska, using portable microwave radar," in Proc. 66th Апnи. Eastern Snow Conf., Jun. 2009, pp. 9-11.

[31] J. Shi and J. Dozier, "Estimation of snow water equivalence using SIR-C/X-SAR. I. Inferring snow density and subsurface properties," IEEE Trans. Geosci. Remote Sens., vol. 38, no. 6, pp. 2465-2474, Nov. 2000.

[32] R. S. Brown, C. R. Duguay, R. P. Mueller, L. L. Moulton, P. J. Doucette, and J. D. Tagestad, "Use of synthetic aperture radar (SAR) to identify and characterize overwintering areas of fish in ice-covered Arctic rivers: A demonstration with broad whitefish and their habitats in the Sagavanirktok River, Alaska," Trans. Amer. Fisheries Soc., vol. 139, no. 6, pp. 1711-1722, 2010.

[33] J. Grunblatt and D. Atwood, "Mapping lakes for winter liquid water availability using SAR on the North Slope of Alaska," Int. J. Appl. Earth Obs., vol. 27, pp. 63-69, Apr. 2013

[34] S. A. Bari and J. Hallett, "Nucleation and growth of bubbles at an icewater interface," J. Glaciol., vol. 13, no. 69, pp. 489-520, 1974.

[35] K. Yoshimura, T. Inada, and S. Koyama, "Growth of spherical and cylindrical oxygen bubbles at an ice-water interface," Cryst. Growth Des., vol. 8, no. 7, pp. 2108-2115, 2008.

[36] N. Kozlenko and M. O. Jeffries, "Bathymetric mapping of shallow water in thaw lakes on the North Slope of Alaska with spaceborne imaging radar," Arctic, vol. 53, no. 3, pp. 306-316, 2000.

[37] B. Tian et al., "Characterizing C-band backscattering from thermokarst lake ice on the Qinghai-Tibet Plateau," J. Photogramm. Remote Sens., vol. 104, pp. 63-76, Jun. 2015.

[38] B. Michel and R. O. Ramseier, "Classification of river and lake ice," Can. Geotech. J., vol. 8, no. 1, pp. 35-45, 1971.
[39] M. Nolan, G. E. Liston, P. Prokein, J. Brigham-Grette, V. L. Sharpton, and R. Huntzinger, "Analysis of lake ice dynamics and morphology on Lake El'gygytgyn, NE Siberia, using synthetic aperture radar (SAR) and Landsat," J. Geophys. Res., vol. 108, no. D2, pp. ALT3-1-ALT3-12, 2002.

[40] R. Leconte, S. Daly, Y. Gauthier, N. Yankielun, F. Bérubé, and M. Bernier, "A controlled experiment to retrieve freshwater ice characteristics from an FM-CW radar system," Cold Regions Sci. Technol., vol. 55, no. 2, pp. 212-220, 2009.

[41] S. R. Cloude and E. Pottier, "A review of target decomposition theorems in radar polarimetry," IEEE Trans. Geosci. Remote Sens., vol. 34, no. 2, pp. 498-518, Mar. 1996.

[42] W. L. Cameron, N. N. Youssef, and L. K. Leung, "Simulated polarimetric signatures of primitive geometrical shapes," IEEE Trans. Geosci. Remote Sens., vol. 34, no. 3, pp. 793-803, May 1996.

[43] R. Touzi and F. Charbonneau, "Characterization of target symmetric scattering using polarimetric SARs," IEEE Trans. Geosci. Remote Sens., vol. 40, no. 11, pp. 2507-2516, Nov. 2002.

[44] W. An, Y. Cui, and J. Yang, "Three-component model-based decomposition for polarimetric SAR data," IEEE Trans. Geosci. Remote Sens., vol. 48, no. 6, pp. 2732-2739, Jun. 2010.

[45] A. Freeman and S. L. Durden, "A three-component scattering model for polarimetric SAR data," IEEE Trans. Geosci. Remote Sens., vol. 36 no. 3, pp. 963-973, May 1998.

[46] S. R. Cloude, Polarisation. New York, NY, USA: Oxford Univ. Press, 2010, p. 453.

[47] E. Krogager and A. Freeman, "Three component break-downs of scattering matrices for radar target identification and classification," in Proc. PIERS, Noordwijk, The Netherlands, Jul. 1994, p. 391.

[48] J. J. van der Sanden and H. Drouin, "Satellite SAR observations of river ice cover: A RADARSAT-2 (C-band) and ALOS PALSAR (L-band) comparison," in Proc. CGU HS Commun. River Ice Process. Environ., vol. 2. 2011, pp. 179-197.

[49] P. A. Scott, C. V. Bentley, D. C. F. Fayle, and R. I. C. Hansell, "Crown forms and shoot elongation of white spruce at the treeline, Churchill, Manitoba, Canada," Arctic Alpine Res., vol. 19, no. 2, pp. 175-186, 1987.

[50] P. M. Lafleur, A. B. Wurtele, and C. R. Duguay, "Spatial and temporal variations in surface albedo of a subarctic landscape using surface-based measurements and remote sensing," Arctic Alpine Res., vol. 29, no. 3, pp. 261-269, 1997.

[51] L. C. Brown and C. R. Duguay, "A comparison of simulated and measured lake ice thickness using a Shallow Water Ice Profiler," Hydrol. Process., vol. 25, no. 19, pp. 2932-2941, 2011.

[52] M. Sturm and J. A. Holmgren, "Self-recording snow depth probe," U.S. Patent 5864059 A, Jan. 26, 1999.

[53] C. Fierz et al., "The international classification for seasonal snow on the ground," vol. 25. Hydrol., Int. Hydrol. Programme, United Nations Educ., Sci. Cultural Org., Paris, France, 2009.

[54] M. Sturm and G. E. Liston, "The snow cover on lakes of the Arctic Coastal Plain of Alaska, U.S.A.," J. Glaciol., vol. 49, no. 166, pp. 370-380, 2003.

[55] J. M. L. King, R. E. J. Kelly, A. Kasurak, C. R. Duguay, G. Gunn, and J. B. Mead, "UW-scat: A ground-based dual-frequency scatterometer for observation of snow properties," IEEE Geosci. Remote Sens. Lett., vol. 10, no. 3, pp. 528-532, May 2013.

[56] H.-P. Marshall, M. Schneebeli, and G. Koh, "Snow stratigraphy measurements with high-frequency FMCW radar: Comparison with snow micro-penetrometer," Cold Regions Sci. Technol., vol. 47, nos. 1-2, pp. 108-117, 2007

[57] G. E. Gunn, M. Brogioni, C. R. Duguay, G. Macelloni, A. Kasurak, and J. M. L. King, "Observation and modeling of X- and Ku-band backscatter of snow-covered freshwater lake ice," IEEE J. Sel. Topics Appl. Earth Observ. Remote Sens., vol. 8, no. 7, pp. 3629-3642, Jul. 2105, doi: 10.1109/JSTARS.2015.2420411.2015.

[58] G. E. Gunn, C. R. Duguay, L. C. Brown, J. M. L. King, D. Atwood, and A. Kasurak, "Freshwater lake ice thickness derived using surface-based $\mathrm{X}-$ and Ku-band FMCW scatterometers," Cold Regions Sci. Technol., vol. 120 , pp. 115-126, Dec. 2015

[59] W. A. Cumming, "The dielectric properties of ice and snow at 3.2 centimeters," J. Appl. Phys., vol. 23, no. 7, pp. 768-773, 1952.

[60] Y. Yamaguchi, T. Moriyama, M. Ishido, and H. Yamada, "Fourcomponent scattering model for polarimetric SAR image decomposition," IEEE Trans. Geosci. Remote Sens., vol. 43, no. 8, pp. 1699-1706, Aug. 2005. 
[61] M. O. Jeffries, K. Morris, and C. R. Duguay, "Lake ice growth and decay in central Alaska, USA: Observations and computer simulations compared," Ann. Glaciol., vol. 40, pp. 195-199, Sep. 2005.

[62] T. Inada, T. Hatakeyama, and F. Takemura, "Gas-storage ice grown from water containing microbubbles," Int. J. Refrig., vol. 32, no. 3, pp. $462-471,2009$.

[63] K. Yoshimura, T. Inada, and S. Koyama, "Growth of spherical and cylindrical oxygen bubbles at an ice-water interface," Cryst Growth Des., vol. 8, no. 7, pp. 2108-2115, 2008

[64] P. S. Wei and S. Y. Hsiao, "Pore shape development from a bubble captured by a solidification front," Int. J. Heat Mass Transf., vol. 55, nos. 25-26, pp. 8129-8138, 2012.

[65] K. Hayashi, Y. Sato, Y. Yamaguchi, and H. Yamada, "Polarimetric scattering analysis for a finite dihedral corner reflector," Inst. Electron., Inf., Commun. Eng., vol. E89-B, no. 1, pp. 191-195, 2006.

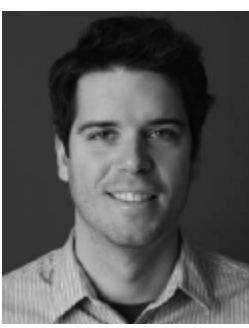

Grant E. Gunn (S'15-M'17) received the M.Sc degree in geomatics and remote sensing applications in 2010 and the Ph.D. degree in microwave remote sensing, both from the University of Waterloo, Waterloo, ON, Canada.

$\mathrm{He}$ is currently an Assistant Professor with the Department of Geography, Environment, and Spatial Sciences, Michigan State University, East Lansing, MI, USA. His research interests include active microwave remote sensing of Arctic freshwater and saline ice using ground-based and spaceborne platforms.

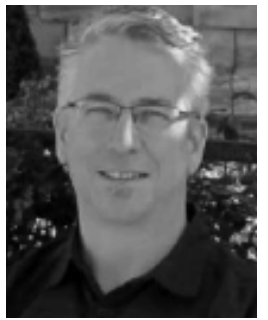

Claude R. Duguay received the B.Sc. degree from the Université de Montréal, Montreal, QC, Canada, the M.A. degree from the State University of New York at Buffalo, Buffalo, NY, USA, and the Ph.D. degree from the University of Waterloo, Waterloo, ON, Canada.

From 2008 to 2012, he was a Member and the Founding Director of the Interdisciplinary Centre on Climate Change (IC3), University of Waterloo, where he is currently a Professor of earth systems science and geomatics with the Department of Geography and Environmental Management. His research interests include remote sensing, field observations and modeling of cold region processes with the intent of deepening our knowledge, and understanding and predictive capabilities of lake/land-atmosphere/climate interactions.

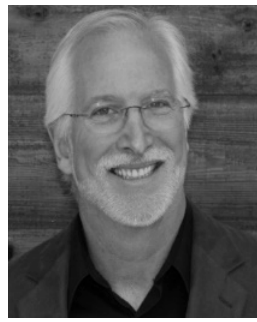

Donald K. Atwood (M'95) received the Ph.D. degree in physics from the Massachusetts Institute of Technology (MIT). In 1992, he joined MIT Sea Grant where he developed Autonomous Underwater Vehicles with specialization in underwater acoustics. He then worked for Raytheon, first as a technical advisor in international environmental programs, then as a manager in atmospheric remote sensing at the NASA Goddard Space Flight Center. With Raytheon Polar Services, he became the Director of Science Support for the U.S. Antarctic Program. In 2003, he joined the Alaska Satellite Facility (ASF), University of Alaska Fairbanks, where he served as the Chief Scientist, focusing on applications of SAR, PolSAR, and interferometry.

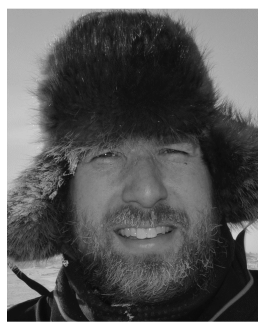

Joshua King received the M.Sc. degree in geography and the Ph.D. degree from the University of Waterloo, Waterloo, ON, Canada, in 2009 and 2014, respectively.

Since 2014, he has been with the Climate Processes Section, Environment and Climate Change Canada, Toronto, ON, Canada, where he is currently a Research Scientist. His research interests include the development of field and remote sensing methods for improved characterization of snow properties on land and sea ice.

Peter Toose received the B.E.S. and M.E.S. degrees in geography from the University of Waterloo, Waterloo, ON, Canada, in 2004 and 2007, respectively.

He is currently a Physical Scientist with the Climate Research Division, Science and Technology Branch, Environment and Climate Change Canada, Toronto, ON, USA. His research interests include using ground, airborne, and spaceborne passive and active microwave sensors in support of the development and validation of satellite-based capabilities to retrieve snow, soil, and ice parameters. 